Universidade de São Paulo

Instituto de Astronomia, Geofísica e Ciências Atmosféricas

Departamento de Astronomia

Laerte Brandão Paes de Andrade

\title{
Sismologia e Modelização de Estrelas Quentes com Rotação Moderada
}

São Paulo

Março de 2010 

Laerte Brandão Paes de Andrade

\section{Sismologia e Modelização de Estrelas Quentes com Rotação Moderada}

Tese apresentada ao Departamento de Astronomia do Instituto de Astronomia, Geofísica e Ciências Atmosféricas da Universidade de São Paulo como parte dos requisitos para a obtenção do título de Doutor em Ciências.

Área de Concentração: Astronomia

Orientador: Prof. Dr. Eduardo Janot Pacheco

São Paulo

Março de 2010 



\section{Agradecimentos}

Agradeço a todos que, de forma direta ou indireta, colaboraram para o direcionamento e concretização deste trabalho.

Agradeço ao Prof. Dr. Eduardo Janot Pacheco, pela orientação presente, discussões e contribuições fundamentais para a conclusão do trabalho, além é claro da sincera e recíproca amizade.

Ao Prof. Dr. Juan Carlos Suárez pelo apoio compreensivo em todos os momentos difíceis.

Aos amigos Rubens Machado, Adriana Pires, Tiago Peixoto, Alexandre Abdo, André Berger e Thiago Assan por todas as discussões e diversões vividas nos últimos anos.

A todos os amigos, colegas, professores e funcionários do Instituto de Astronomia, Geofísica e Ciências Atmosféricas da Universidade de São Paulo, pelo suporte e encorajamento.

Da mesma forma, a todos os amigos, colegas, professores e funcionários do Instituto de Astrofísica de Andalucía que tão bem me acolheram por um breve período.

À FAPESP, pelo apoio financeiro, sob o projeto $n^{o}$ 03/10743-9; e à CAPES, pelo apoio de mesma natureza, sob o projeto $\mathrm{n}^{\circ}$ 1508-06-7.

Por fim, agradeço à minha família: meus pais Arnaldo e Lane, minha irmã Joanna e meu irmão Victor.

Esta tese/dissertação foi escrita em IATEX com a classe IAGTESE, para teses e dissertações do IAG. 



\section{Resumo}

Modelos computacionais existentes de estrelas quentes com rotação moderada ou rápida $\left(v_{r o t, s} \geq 20 \mathrm{~km} / \mathrm{s}\right)$ não reproduzem satisfatoriamente as características das freqüências observadas devido às pulsações não-radiais, como por exemplo splittings e assimetrias. O objetivo do trabalho consiste em melhorar a qualidade de tais modelos de forma a poder cotejá-los com as características observacionais de pulsações não-radiais num processo iterativo que conduzirá a determinar com maior precisão os parâmetros físicos e a estrutura interna de tais estrelas. Em particular, procuramos determinar o perfil radial de rotação no interior dos objetos. Os satélites da geração atual (Corot, Kepler, etc.) permitem medir os parâmetros das pulsações não-radiais com grande sensibilidade de detecção e grande poder de resolução de freqüências. Apresentamos os resultados de nossos cálculos, cotejados com resultados obtidos a partir de observações fotométricas e espectroscópicas (Handler et al. 2005) da estrela de tipo $\beta$ Cephei $\theta$ Ophiuchi $(v \sin i=29 \pm 7 \mathrm{~km} / \mathrm{s}$, Briquet et al. 2007). Com tal procedimento, conseguimos: (i) identificar as características do perfil de rotação interna das estrelas quentes, indispensável para fazer modelos mais realistas; e (ii) simplificar o problema: refazemos o código de cálculo perturbativo contendo apenas os termos dominantes quanto à sensibilidade à rotação, tornando mais preciso e eficiente o cálculo de pulsações não-radiais para as estrelas estudadas. 



\section{Abstract}

Current computational models for hot stars with moderate or rapid rotation $\left(v_{\text {rot }, s} \geq\right.$ $20 \mathrm{~km} / \mathrm{s}$ ) do not satisfactorily reproduce the characteristics of observed frequencies due to non-radial pulsations, for instance, splittings and asymmetries. The goal of this work is to improve the quality of such models in such a way that they better represent observational characteristics of non-radial pulsations, in an iterative process which leads to better precision of physical parameters and internal structure of such stars. In particular, we determine the radial rotation profile in the interior of the objects. Present-day satellites (Corot, Kepler, etc.) allow measurement of non-radial pulsation parameters with great detection sensibility and high-resolution frequency power. We present the results of our calculations, compared with results obtained from photometric and spectroscopic observations (Handler et al. 2005) from the $\beta$ Cephei star $\theta$ Ophiuchi $(v \sin i=29 \pm 7 \mathrm{~km} / \mathrm{s}$, Briquet et al. 2007). With such a procedure, we were able to: (i) identify the characteristics of internal rotation profiles of hot stars, which are needed for more realistic models'and (ii) simplify the problem: we redid the perturbative calculation code including only the main terms in relation to the sensibility to rotation, yielding a more precise and efficient calculus of non-radial pulsation for the stars studied. 



\section{Lista de Figuras}

1.1 Diagrama de propagação para um modelo solar. Curvas sólidas representam $\omega_{+} / 2 \pi$ e curvas hachuradas $\omega_{-} / 2 \pi$. As curvas representam $l=1,5,50$ e 500 . Em todos os casos, $\omega_{ \pm}$é função crescente de $l$ para $r / R$ fixo, o que permite a identificação das curvas. Figura de Deuber \& Gough (1984). . . . . . . .

1.2 Autofunções de deslocamento radial para alguns modos-p e modos-g selecionados, para um modelo solar normal. Figura de Libbrecht (1988). . . . .

1.3 Espectro de frequências para modos p de baixo $l$. O destaque é um diagrama de frequências superpostas, com período de repetição $136 \mu \mathrm{Hz}$, demonstrando o espaçamento regular previsto pela teoria assintótica. Figura de Libbrecht (1988). . . . . . . . . . . . . . . . . .

1.4 Autofrequências em função do grau $l$, computadas para um modelo solar normal. Alguns valores da ordem radial $n$ estão indicados. A partir de modelo de Dalsgaard (2003) . . . . . . . . . . . . . . . .

2.1 Espectros retificados dos alvos observados na região centro de observação de CoRoT. De cima para baixo, a temperatura efetiva é decrescente. . . . .

4.1 Espectro de amplitude esquemático da estrela $\theta$ Oph. As freqüências $f_{4}, f_{6}$ e $f_{7}$ constituem o tripleto do modo $p 1$ (Handler et al. 2005) . . . . . . . . . 54 
4.2 Freqüências do modo $p 1(l=1, m=0)$ em $\mu \mathrm{Hz}$ em função da temperatura efetiva para conjuntos de modelos com velocidade de rotação superficial $v_{\text {rot }, s}=20 \mathrm{~km} / \mathrm{s}$ e taxa de overshooting $\alpha=0.40$, para três massas distintas: 7.9, 8.2 e 8.5 massas solares. A largura da linha horizontal representa a incerteza em $T_{\text {eff }}$ de $\theta$ Ophiuchi de acordo com Briquet et al. (2007), e seu valor é igual a freqüência observada $p 1\left(f_{6}\right)$ de Handler et al. (2005). O asterisco marca o modelo mais próximo de $\nu(\mathrm{p} 1, m=0)$ observada. . . .

4.3 Splittings (a) e assimetrias (b) do modo $p 1(l=1)$ em $\mu \mathrm{Hz}$ como função da temperatura efetiva para uma série de modelos com velocidade de rotação $v_{\text {rot }, s}=20 \mathrm{~km} / \mathrm{s}$ e taxa de overshooting $\alpha=0.40$. A área cinza representa a incerteza na temperatura efetiva $T_{\text {eff }}$ de $\theta$ Ophiuchi e a linha horizontal representa a freqüência $p 1(l=1, m=0)$ observada. O asterisco marca o modelo mais próximo da freqüência observada. . . . . . . . . . . . .

4.4 Perfis de rotação modificados do modelo 2 da tabela 4.1, assumindo (a) distribuição radial linear (linhas retas), (b) taxa de rotação central variável (shellular), e (c) ajustes de polinômios de diferentes ordens ao perfil original. A linha cheia mostra o perfil de rotação original para comparação. . . . . .

4.5 Dependência radial dos kernels para os modos $g 2, g 1, p 1$ e $p 2(l=1)$ calculados a partir dos modelos com perfis de rotação modificados em função da coordenada radial (normalizada em relação ao raio da estrela). . . . . . .

4.6 Diferenças absolutas entre os kernels obtidos com modelos com perfis de rotação lineares e o modelo de referência, para os modos $g 2, g 1, p 1$ e $p 2$. Os valores $\Delta K_{i}$ representam a porcentagem da taxa de rotação do núcleo em relação ao modelo de referência. . . . . . . . . . . . . . . . . . . .

4.7 O mesmo que a figura 4.6 para modelos com perfil de rotação "shellular". Os valores de $\Delta K_{i}$ têm significado equivalente. . . . . . . . . . . . . . 62

4.8 O mesmo que a figura 4.6 para modelos com ajuste polinomial do perfil de rotação. . . . . . . . . . . . . . . . . . . 
4.9 Assimetrias $\left(A_{j}\right)$ dos tripletos $g_{2}(\mathrm{a}), g_{1}(\mathrm{~b}), p_{1}(\mathrm{c})$ e $p_{2}(\mathrm{~d})$, computadas para os 12 perfis de rotação considerados. A linha reta representa, em cada caso, a assimetria do modelo de referência (modelo 2 na tabela 4.1). A linha hachurada em (c) representa a assimetria observada de $\theta$ Ophiuchi conforme determinada por Handler et al. (2005). Para identificar os modelos consideramos a seguinte representação: asteriscos para modelos de perfil linear (da esquerda para a direita, modelos vão de $\eta_{s}=25 \%$ para $100 \%$, respectivamente), cruzes para modelos polinomiais (da esquerda para a direita, modelos vão da ordem 2 para ordem 6), e losangos para modelos "shellulares" (da esquerda para a direita, modelos vão de $\eta_{s}=25 \%$ até $75 \%$, respectivamente). . . . . . . . . . . . . . . . .

4.10 Assimetrias $\left(A_{j}\right)$ do tripleto $p 1$ computadas para as 12 variações de perfis para os três modelos na tabela 4.1. A linha reta representa, em cada caso, a assimetria do modelo de referência. A linha hachurada representa a assimetria observada de $\theta$ Ophiuchi conforme determinada por Handler et al. (2005).

4.11 Termos $Y_{1}$ dos tripletos $g_{2}(\mathrm{a}), g_{1}(\mathrm{~b}), p_{1}(\mathrm{c})$ and $p_{2}(\mathrm{~d})$, computados para os 12 diferentes perfis de rotação considerados (modelo de referência 1 na tabela 4.1). A linha reta representa, em cada caso, o valor do modelo de referência. Para identificar os modelos consideramos a seguinte representação: asteriscos para modelos de perfil linear (da esquerda para a direita, modelos vão de $\eta_{s}=25 \%$ para $100 \%$, respectivamente), cruzes para modelos polinomiais (da esquerda para a direita, modelos vão da ordem 2 para ordem 6), e losangos para modelos "shellulares" (da esquerda para a direita, modelos vão de $\eta_{s}=25 \%$ até $75 \%$, respectivamente) . . . . . . . . . . . . . .

4.12 Termos $Y_{2}$ dos tripletos $g_{2}(\mathrm{a}), g_{1}(\mathrm{~b}), p_{1}$ (c) and $p_{2}(\mathrm{~d})$, computados para os 12 diferentes perfis de rotação considerados (modelo de referência 1 na tabela 4.1). A linha reta representa, em cada caso, o valor do modelo de referência. Modelos seguem a mesma representação da figura 4.11. . . . . 70

4.13 Observação espectroscópica da estrela CoRoT-ID 102761769. . . . . . . . . 73 
4.14 Close-ups de regiões espectrais de interesse. De cima para baixo: $\mathrm{H} \alpha, \mathrm{H} \beta$,

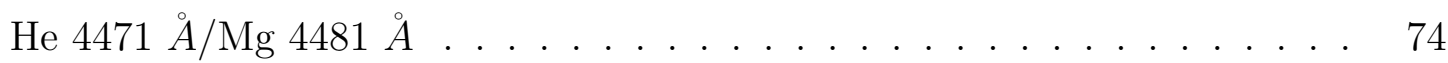

4.15 Diagrama HR mostrando traçados evolutivos calculados para CoRoT 102761769, para três diferentes valores de massa $\left(3.6,3.8\right.$ and $\left.4.0 M_{\odot}\right)$ e duas velocidades de rotação equatorial (90 e $120 \mathrm{~km} / \mathrm{s}$ ). A área hachurada corresponde a incerteza na temperatura efetiva. . . . . . . . . . . . . 76

4.16 Frequências dos modos $g_{1}$ a $g_{5}(l=1, m=0)$ em $\mu \mathrm{Hz}$ em função da temperatuva efetiva para conjuntos de modelos com 3.8 massas solares e $v_{\text {rot }, s}=120 \mathrm{~km} / \mathrm{s}$. A caixa cinza representa a incerteza em $T_{\text {eff }}$ tal qual derivada a partir de Huang \& Gies (2006). A linha horizontal representa a frequência $f_{1}$ observada. A cruz marca o modelo mais próximo de $\nu\left(g_{5}, m=\right.$ 0) observado. . . . . . . . . . . . . . . . . . . . . 77 


\section{Lista de Tabelas}

2.1 Relação das estrelas observadas com telescópio de 1,6m do LNA no campo centro do satélite. O tipo espectral foi obtido de CDS-Simbad. . . . . . . . 38

2.2 Classes de luminosidade de Morgan-Keenan. . . . . . . . . . . . . . . . . . 38

2.3 Resultados obtidos para velocidades de rotação e classificação espectral das estrelas analisadas. $\left(^{*}\right)$ Estrelas que apresentam emissão em linhas de HeI.

2.4 Relação das estrelas observadas com telescópio de 1,6m (OPD) no campo centro do satélite. Informações retiradas de CDS/Simbad. . . . . . . . . . 41

4.1 Melhores modelos para a estrela $\theta$ Ophiuchi, todos com $M=8.5 M_{\odot}$. Da esquerda para à direita, ov é o overshooting, $T_{\text {eff }}$ a temperatura efetiva (K em log), $L$ a luminosidade, $\bar{\rho}$ a densidade média (cgs), a idade (em Myr), $v_{r o t, s}$ a velocidade de rotação linear na superfície e $\nu_{p 1_{0}}$ a freqüência do modo $p 1(l=1, m=0)$ em $\mu \mathrm{Hz} \ldots \ldots \ldots \ldots \ldots$

4.2 Valores dos coeficientes de segunda ordem $X_{i}$ e $Y_{i}$ (Suárez et al. 2006) para o modo $g_{2}(l=1)$, calculados para o modelo de referência (modelo 1 na tabela 4.1 e modelos com perfis de rotação modificados para os três cenários discutidos. . . . . . . . . . . . . . . . .

4.3 Valores dos coeficientes de segunda ordem $X_{i}$ e $Y_{i}$ (Suárez et al. 2006) para o modo $g_{1}(l=1)$, calculados para o modelo de referência (modelo 1 na tabela 4.1 e modelos com perfis de rotação modificados para os três cenários discutidos. . . . . . . . . . . . . . . . . . 
4.4 Valores dos coeficientes de segunda ordem $X_{i}$ e $Y_{i}$ (Suárez et al. 2006) para o modo $p_{1}(l=1)$, calculados para o modelo de referência (modelo 1 na tabela 4.1 e modelos com perfis de rotação modificados para os três cenários discutidos. . . . . . . . . . . . . . . . . . 67

4.5 Valores dos coeficientes de segunda ordem $X_{i}$ e $Y_{i}$ (Suárez et al. 2006) para o modo $p_{2}(l=1)$, calculados para o modelo de referência (modelo 1 na tabela 4.1 e modelos com perfis de rotação modificados para os três cenários discutidos. . . . . . . . . . . . . . . . . . . . . . 68

4.6 Modelos que melhor se aproximam da frequência observada $f_{1}$ para cada uma dos seis traçados de evolução considerados. As frequências são todas compatíveis com um modo de pulsação $g_{5}(l=1, m=0)$. . . . . . . 


\section{Sumário}

1. Introdução às pulsações não radiais . . . . . . . . . . . . . . . . . . . . . . . . . 17

1.1 Informações obtidas a partir das frequências . . . . . . . . . . . . . . . 18

1.2 Efeitos de rotação . . . . . . . . . . . . . . . . . . . . 27

1.2.1 Efeito de velocidades de larga escala nas frequências de oscilação . . 28

1.2.2 Splittings de rotação . . . . . . . . . . . . . . . . . . . . 31

1.2.3 Assimetrias do splitting rotacional . . . . . . . . . . . . . . . . 32

2. Observações de estrelas quentes com satélite CoRoT . . . . . . . . . . . . 35

2.1 Introdução sobre o satélite CoRoT, long/short runs . . . . . . . . . . . . . 35

2.2 Classificação espectral de alvos nos campos de observação do satélite . 36

2.2.1 Primeiro anúncio de oportunidade . . . . . . . . . . . . . . 36

2.2.2 Segundo anúncio de oportunidade . . . . . . . . . . . . . . . . 37

3. Modelos de pulsações de estrelas quentes . . . . . . . . . . . . . . . . . . . . . . 43

3.1 Modelo de estrutura estelar CESAM . . . . . . . . . . . . . . . . . . 43

3.1.1 Procedimento . . . . . . . . . . . . . . . . . 45

3.1 .2 Métodos numéricos . . . . . . . . . . . . . . . . 47

3.1 .3 Rotação . . . . . . . . . . . . . . . . . . . . . . . . . 48

3.1.4 Convecção . . . . . . . . . . . . . . . . . . . . . . . . . . . . . 49

3.1.5 Equação de estado e opacidade . . . . . . . . . . . . . . . . . . . 49

3.2 Modelo de cálculo de frequências de oscilação FILOU . . . . . . . . . . . . 50

3.2 .1 Oscilações adiabáticas . . . . . . . . . . . . . . . 51

3.2 .2 Estrutura e esquema do cálculo . . . . . . . . . . . . . . . 51 
4. Aplicações para estrelas quentes de rotação moderada . . . . . . . . . . . . . . . 53

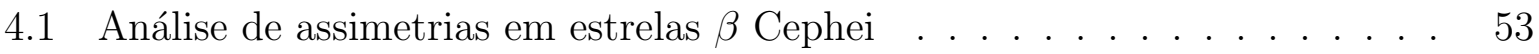

4.1.1 Variação dos perfis de rotação . . . . . . . . . . . . . . 55

4.1.2 Kernels do splitting rotacional, assimetrias e termos de segunda ordem 58

4.2 Identificação de modos de oscilação em estrelas Be de baixa rotação . . . . 71

4.2.1 Estrela Corot-ID 102761769 - observações fotométricas . . . . . . . 72

4.2 .2 Observações espectroscópicas em terra . . . . . . . . . . . . 72

4.2 .3 Pulsações não-radiais . . . . . . . . . . . . . . . . . . . . . . . 73

5. Conclusões e Perspectivas . . . . . . . . . . . . . . . . . . . . . . 79

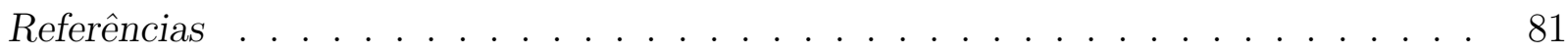

Apêndice $\quad 85$

A. Analysis of asymmetries in rotational splitted multiplets of $\beta$ Cephei stars . . . 87

B. Photometric variability of the Be star CoRoT-ID 102761769 . . . . . . . . . 89 
Capítulo 1

\section{Introdução às pulsações não radiais}

Nos últimos quinze anos, estudo das pulsações estelares não-radiais (PNR) tem fornecido importantes subsídios para a compreensão da estrutura interna e evolução das estrelas e para testar nossos modelos (p. ex., Christensen-Dalsgaard \& Dziembowski 2000). A disciplina que se ocupa dessa área, a Sismologia Estelar, utiliza o fato de que a natureza das oscilações observadas na superfície dos objetos é ditada pelas características físicas da cavidade onde elas se desenvolvem; elas agem assim como sondas, fornecendo informações sobre a estrutura interna das estrelas, antes restritas apenas à observação dos neutrinos, produzidos nas regiões centrais. Descobriu-se que as pulsações nas estrelas podem ser essencialmente de dois tipos: modos acústicos (ou p), onde a força restauradora é a pressão do gás e modos de gravidade (ou g), controlados pela flutuabilidade do meio.

Heliossismologia e Anãs Brancas. No caso do Sol, a resolução do disco permitiu a identificação de milhares de modos de oscilações não radiais. Isso resultou na obtenção de informações com precisão inédita sobre a física do interior solar (espessura da camada convectiva, perfil de rotação, variação radial da velocidade do som, abundância do Hélio; Christensen-Dalsgaard 2003). As PNR solares são produzidas por mecanismos estocásticos, que produzem modos acústicos. Descobriu-se nas Anãs Brancas, a partir de observações multi-sítio (campanhas WET, p. ex. Kepler et al. 1995), a presença de modos g, produzidos pelo mecanismo de opacidade $\kappa$. Nesses objetos, isso levou à determinação de parâmetros físicos com grande precisão (massa, composição química, estratificação interna, campo magnético, ângulo de visada...).

Astrossismologia e o DHR. Hoje sabe-se que, além das estrelas de tipo solar e ABs, existem por todo o DHR objetos que apresentam PNR (com modos p e g), como as $\delta$ 
Scuti, Am/Ap, $\beta$ Cephei, OBA com linhas de emissão, gigantes vermelhas e Wolf-Rayets. Com o progresso dos modelos teóricos, a determinação de parâmetros físicos via sismologia vem se estendendo a outros tipos de objetos.

Sismologia Comparada e Evolução Estelar. Estudos sismológicos comparativos de diversos tipos de estrelas levarão a avanços importantes em nossos conhecimentos sobre as mudanças estruturais que ocorrem durante sua evolução. O satélite franco-europeu COROT trouxe um enorme avanço nesse sentido. Foi lançado em 2006 e faz fotometria de alta precisão de estrelas de vários tipos por longos períodos (até seis meses). Isso produz excelente resolução em freqüência, permitindo a identificação das características dos multipletos das oscilações, possibilitando uma análise sismológica com precisão inédita de um grande número de objetos (p. ex., A\&A, Vol. 506, 2009). A astrossismologia propicia, assim, um salto qualitativo na compreensão do funcionamento desses sistemas físicos que constituem as estrelas.

\subsection{Informações obtidas a partir das frequências}

As equações básicas que descrevem as deformações e as oscilações de uma estrela são as equações de hidrodinâmica para a conservação da massa (eq. 1.1), momento (eq. 1.2), e energia (eq. 1.4). Elas nos permitirão determinar as propriedades do gás estelar (suposto contínuo), tais como a pressão $p(\vec{r}, t)$, densidade $\rho(\vec{r}, t)$ e velocidade instantânea $\vec{v}(\vec{r}, t)$. Onde $\vec{r}$ é o vetor posição no referencial de um observador estacionário.

$$
\begin{gathered}
\frac{d \rho}{d t}+\rho \vec{\nabla} \cdot \vec{v}=0 \\
\rho \frac{d \vec{v}}{d t}=-\vec{\nabla} p-\rho \vec{\nabla} \Phi
\end{gathered}
$$

onde $\Phi$ representa o potencial gravitacional, que satisfaz a equação de Poisson:

$$
\nabla^{2} \Phi=4 \pi G \rho \quad \text { ou } \quad \Phi(\vec{r}, t)=-G \int_{V} \frac{\rho\left(\vec{r}^{\prime}, t\right) d V}{|\vec{r}-\vec{r}|}
$$

Por fim, obtemos uma relação entre $p$ e $\rho$ a partir das equações termodinâmicas:

$$
\rho \frac{d q}{d t}=\rho \epsilon-\vec{\nabla} \cdot \vec{F}
$$


onde $\epsilon$ é a taxa de geração de energia (por exemplo, de reações nucleares) por unidade de massa, e $\vec{F}$ é o fluxo de energia. Em geral, a radiação é o único contribuinte significativo, e, de acordo com Mihalas \& Mihalas (1984):

$$
\vec{F}=-\frac{4 a \tilde{\mathrm{c}} T^{3}}{3 \kappa \rho} \vec{\nabla} T
$$

onde $\kappa$ é a opacidade, c̃ a velocidade da luz e $a$ é a constante de densidade de radiação.

Para calcular as frequências das oscilações estelares, as complicações da equação de energia podem ser dribladas, sem perda de precisão, desprezando o termo de aquecimento. Dessa forma, o movimento ocorre adiabaticamente. Usando as identidades termodinâmicas, a relação entre $p$ e $\rho$ torna-se

$$
\frac{d p}{d t}=\frac{\Gamma_{1} p}{\rho} \frac{d \rho}{d t}
$$

sendo o expoente de Chandrasekhar dado por

$$
\Gamma_{1}=\left(\frac{\partial \ln p}{\partial \ln \rho}\right)_{a d}
$$

As equações (1.1), (1.2), (1.3) e (1.6) juntas formam um conjunto completo de equações para o movimento adiabático. Tal conjunto ainda é muito complexo para ser analisado, mesmo numericamente (por exemplo, Nordlund \& Stein 1989). Sendo assim, certas simplificações são necessárias.

Sabemos que as oscilações solares consistem de modos de baixa amplitude, que podem assim ser tratadas como pequenas perturbações sobre um estado de equilíbrio estático. Podemos obter o estado de equílibrio desprezando todas as derivadas temporais. A equação de continuidade, por exemplo, é trivialmente satisfeita. Consideraremos o caso de uma estrela sem rotação, sem campo magnético e sem movimentos convectivos. Sob essas hipóteses, o estado de equilíbrio é esfericamente simétrico e o sistema de equações pode ser reescrito em coordenadas polares esféricas, na forma familiar das equações de estrutura estelar:

$$
\frac{d p_{0}}{d r}=-g_{0} \rho_{0}
$$




$$
\begin{gathered}
g_{0}=\frac{G}{r^{2}} \int_{0}^{r} 4 \pi \rho_{0} r^{\prime 2} d r^{\prime}=\frac{G m_{0}}{r^{2}} \\
\frac{d L_{0}}{d r}=4 \pi r^{2} \rho_{0} \epsilon_{0} \\
\frac{d T_{0}}{d r}=-\frac{3 \kappa_{0} \rho_{0}}{16 \pi r^{2} a \tilde{\mathrm{c}} T_{0}^{3}} L_{0}
\end{gathered}
$$

onde $L_{0}=4 \pi r^{2} F_{r, 0}$ é o fluxo total de energia pela esfera de raio $r$.

A perturbação em torno do estado de equilíbrio de uma quantidade escalar, por exemplo, a pressão, resultando da excitação de um único modo de oscilação, pode ser caracterizada, em coordenadas esféricas, por três números quânticos, $n, l$ e $m$ :

$$
\xi(r, \theta, \phi, t)=\operatorname{Re}\left[\Xi_{n, l}(r) Y_{l, m}(\theta, \phi) \exp \left(i \omega_{n l m} t\right)\right]
$$

onde $\Xi(r)$ é uma função de onda radial com $n$ nós radiais, $\omega_{n l m}$ é a frequência angular do modo, e $Y_{l, m}(\theta, \phi)$ é um harmônico esférico de grau $l$ e ordem azimutal $m$ dado por:

$$
Y_{l, m}(\theta, \phi)=P_{l}^{m}(\cos \theta) e^{i m \phi}
$$

onde $P_{l}^{m}$ é a função de Legendre associada a $l$ e $m$.

Para cada grau $l$, existem diversas possibilidades de autofunções $\Xi(r)$. Estas são diferenciadas pela ordem radial $n$. Dessa forma, $n$ indica a componente vertical do número de onda, e $l$ sua componente horizontal.

Como dito, em uma primeira aproximação uma estrela pode ser considerada esfericamente simétrica. Assim, todas as orientações de eixos de coordenadas devem ser equivalentes. As autofrequências $\omega$ não podem portanto depender da ordem azimutal $m$, que mede o número de nós no equador, e assim depende das coordenadas escolhidas.

As equações de fluido linearizadas, incluindo as equações de energia e momento, a equação de continuidade, e a equação de estado, formam um sistema de quarta ordem de equações diferenciais ordinárias para os autovalores $\omega_{n l m}$, que é normalmente resolvido numericamente utilizando-se um modelo pré-existente.

Para se ter uma idéia do significado físico da solução do sistema, seguiremos o exemplo dado por Deubner \& Gough (1984). Se o comprimento de onda de oscilação é muito menor 
que o raio estelar, os efeitos locais de geometria esférica na dinâmica podem ser ignorados. Então as equações de movimento para oscilações adiabáticas podem ser reduzidas, da maneira escolhida por Lamb (1932), resultando em:

$$
\frac{\partial^{2} \Psi}{\partial r^{2}}+K^{2} \Psi=0
$$

onde $\Psi=\rho^{1 / 2} c^{2} \vec{\nabla} \cdot \xi$, e $\rho$ e $c$ indicam, respectivamente, a densidade e a velocidade do som no estado de quilíbrio. Perturbações no potencial gravitacional também foram ignoradas. A componente vertical do número de onda $K$ é dada por:

$$
K^{2}=\frac{\omega^{2}-\omega_{c}^{2}}{c^{2}}+\frac{l(l+1)}{r^{2}}\left(\frac{N^{2}}{\omega^{2}}-1\right)
$$

onde:

$$
\omega_{c}^{2}=\frac{c^{2}}{4 H^{2}}\left(1-2 \frac{\partial H}{\partial r}\right)
$$

sendo $H$ a escala de altura de densidade, e:

$$
N^{2}=g\left(\frac{1}{H}-\frac{g}{c^{2}}\right)
$$

é o quadrado da frequência de flutuabilidade (buoyancy), e $g$ é a magnitude de aceleração devida à gravidade.

A equação 1.14 é uma ótima aproximação exceto próximo de $r=0$, onde efeitos de curvatura passam a ter importância. Porém, como será visto a seguir, apenas modos com $l \ll n$ penetram suficientemente fundo na estrela para que os erros introduzidos pela aproximação tenham efeito significativo nas soluções.

Para que as soluções de (1.14) sejam ondas, é necessário que $K^{2}>0$. Para modos radiais (esfericamente simétricos, $l=0$ ), isso ocorre apenas quando $\omega$ supera a frequência crítica $\omega_{c}$, como pode ser visto diretamente da equação 1.15. Trata-se de uma generalização da frequência de corte de Lamb. Para modos de oscilação não-radiais, é conveniente reescrever (1.15) na forma:

$$
c^{2} K^{2}=\omega^{2}\left(1-\frac{\omega_{+}^{2}}{\omega^{2}}\right)\left(1-\frac{\omega_{-}^{2}}{\omega^{2}}\right)
$$

onde: 


$$
\omega_{ \pm}^{2}=\frac{1}{2}\left(S_{l}^{2}+\omega_{c}^{2}\right) \pm\left[\frac{1}{4}\left(S_{l}^{2}+\omega_{c}^{2}\right)^{2}-N^{2} S_{l}^{2}\right]^{1 / 2}
$$

E por fim,

$$
S_{l}^{2}=\frac{c}{r}[l(l+1)]^{1 / 2}
$$

que é normalmente chamada de frequência de Lamb. Da equação 1.18, temos que $K^{2}>0$ sempre que $\omega_{ \pm}^{2}$ são complexos ou quando:

1. $\omega^{2}>\omega_{-}^{2}$ e $\omega^{2}>\omega_{+}^{2}$;

2. $\omega^{2}<\omega_{-}^{2}$ e $\omega^{2}<\omega_{+}^{2}$.

Os dois casos descrevem duas classes de modos normais de uma estrela. O primeiro é o acústico ou modo-p, para o qual a força restauradora predominante é a pressão. O segundo é o modo gravitacional ou modo-g, para o qual a gravidade atua como força de restauração.

As frequências $\omega_{ \pm}$estão plotadas na figura 1.1 para o caso do Sol. As linhas horizontais representam modos; elas são contínuas nas regiões em que nenhuma das condições é satisfeita. Este diagrama de propagação mostra graficamente como ondas podem ser aprisionadas no interior solar para formar ondas estáveis. Os modos-p, por exemplo, podem propagar-se no interior do Sol, mas são refletidos por uma fronteira externa na superfície estelar e por uma fronteira interna que depende da frequência e $l$. Os modos-g podem se propagar no interior solar profundo, mas são refletidos em uma camada externa na base da zona de convecção do Sol. Os modos cromosféricos observados acima da superfície solar provavelmente não representam soluções de modos de oscilação, dadas as heteregoneidades da cromosfera.

Para um modo normal aprisionado no interior da fotosfera, a condição de existência é essencialmente que um número inteiro de metade do comprimento de onda caiba entre as fronteiras interna e externa, ou seja,

$$
\int_{r_{\text {int }}}^{r_{\text {ext }}} K d r \simeq n \pi
$$

Da figura 1.1, vê-se que os modos-p são refletidos na superfície ou abaixo da fotosfera, se sua frequência é menor que a frequência de corte acústica, aproximadamente $\nu_{c} \simeq 5,5 \mathrm{mHz}$. 


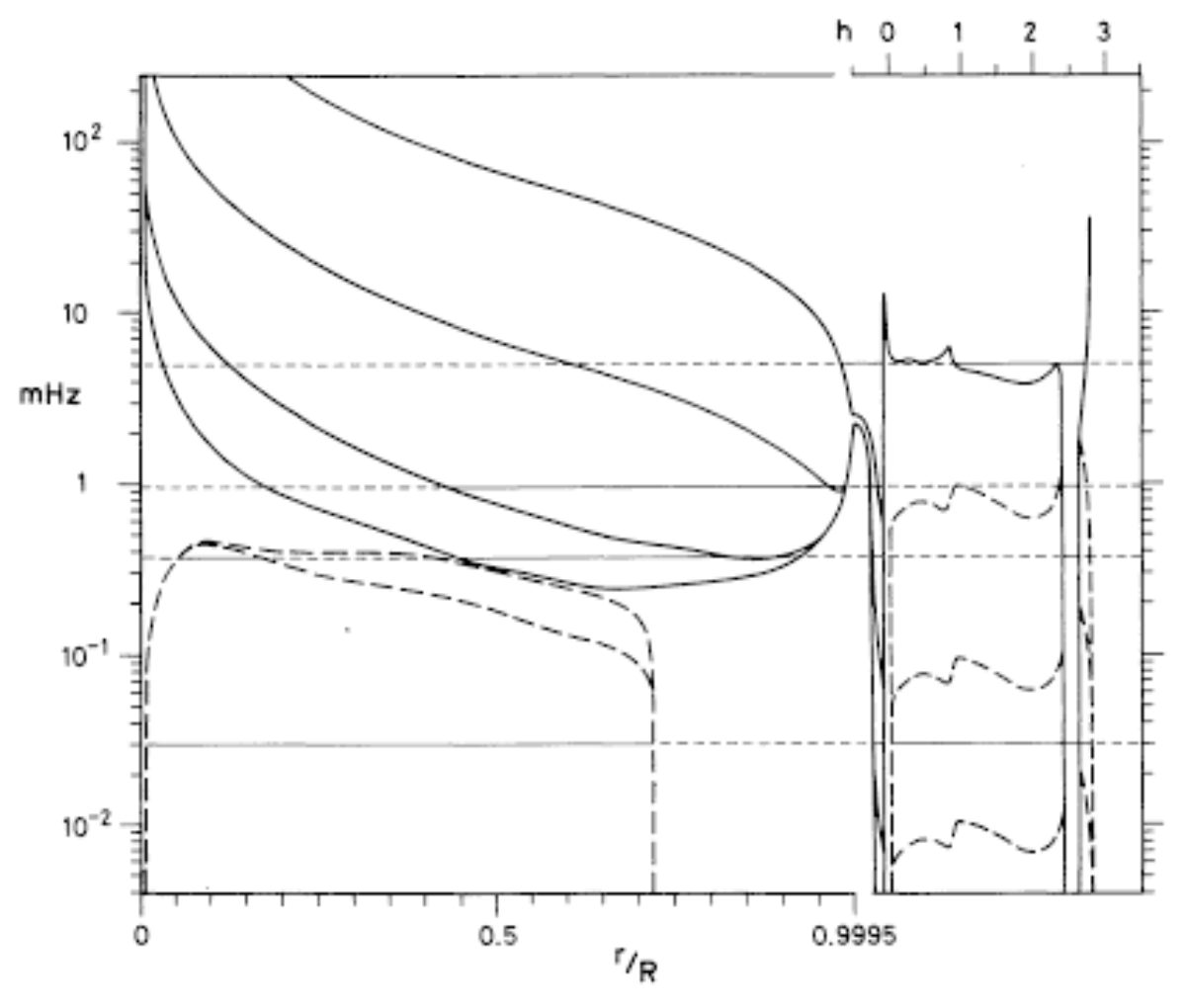

Figura 1.1: Diagrama de propagação para um modelo solar. Curvas sólidas representam $\omega_{+} / 2 \pi$ e curvas hachuradas $\omega_{-} / 2 \pi$. As curvas representam $l=1,5,50$ e 500. Em todos os casos, $\omega_{ \pm}$é função crescente de $l$ para $r / R$ fixo, o que permite a identificação das curvas. Figura de Deuber \& Gough (1984). 
Acima dessa frequência, os modos não estão presos no interior do Sol e podem, dessa forma, dissipar sua energia rapidamente na cromosfera. Percebe-se ainda que o ponto extremo dos modos de alta frequência está mais próximo da atmosfera que para modos de baixa frequência.
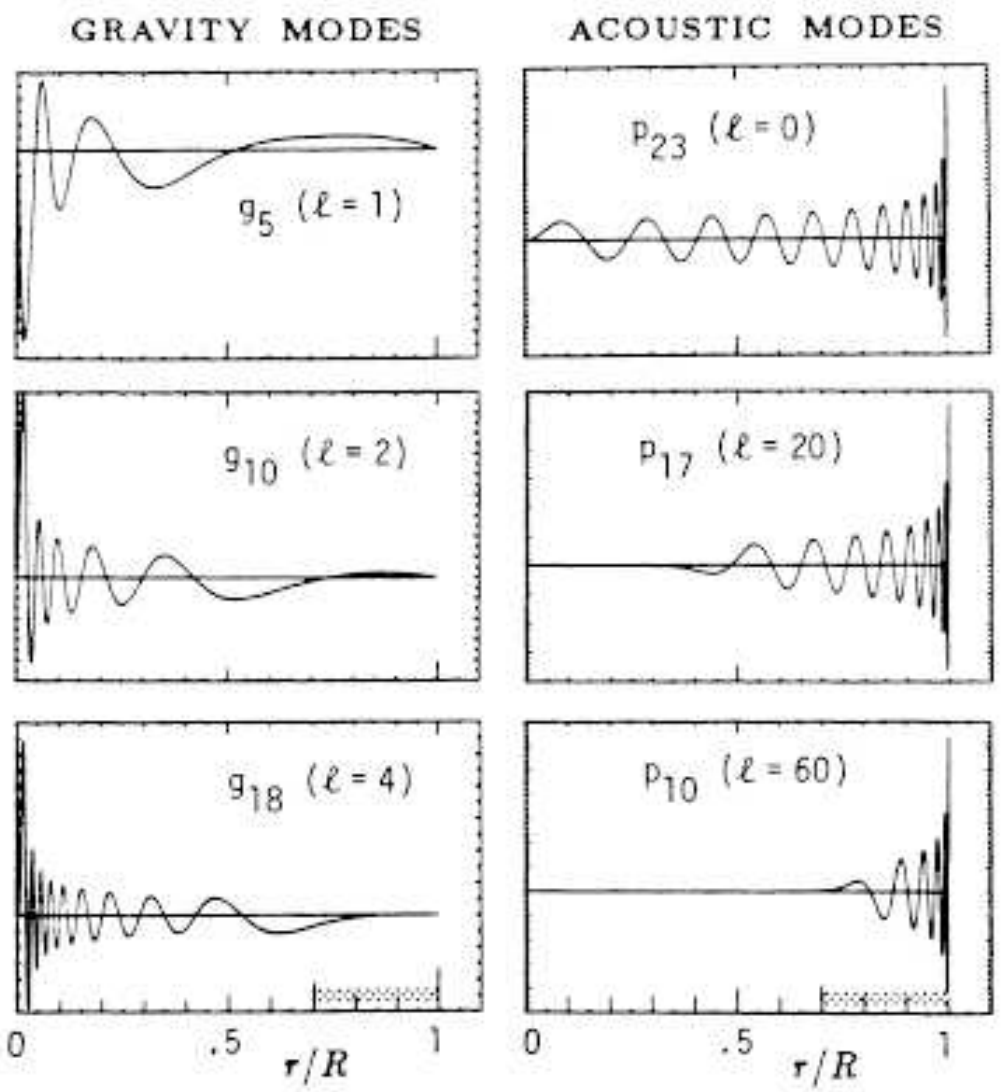

Figura 1.2: Autofunções de deslocamento radial para alguns modos-p e modos-g selecionados, para um modelo solar normal. Figura de Libbrecht (1988).

O ponto extremo interior depende tanto de $l$ quanto da frequência, e é dado por $r_{\text {int }} \simeq$ $c\left(R_{\text {int }}\right) l / \omega$. Assim, modos-p de baixo $l$ penetram mais fundo no interior solar que modos de alto $l$ de mesma frequência. A condição de contorno externa não varia muito com $l$, resultado que pode ser visto de forma esquemática na figura 1.2. Na superfície da cavidade acústica, próxima a superfície solar, as ondas produzem oscilações visíveis que revelam seu período e seu comprimento de onda horizontal (e logo, o valor de $l$ ). A partir dessas quantidades, a velocidade do som na base da cavidade pode ser então calculada.

Nota-se ainda na figura que os deslocamentos dos modos-p são principalmente radiais 
na superfície solar.

Uma expressão assintótica para as frequências quando $n / l \gg 1$ foi derivada por Tassoul (1980), que diz:

$$
\nu_{n l} \simeq \nu_{0}\left(n+\frac{1}{2} l+\epsilon\right)+\delta_{n l}
$$

onde:

$$
\nu_{0}=\left(2 \int_{0}^{R} \frac{d r}{c}\right)^{-1} \simeq 135 \mu \mathrm{Hz}
$$

O resultado indica que as frequências estariam uniformemente espaçadas, na aproximação de baixo $l$. De fato, tal comportamento pode ser observado em um espectro de frequências resultante da observação solar (figura 1.3). Para $n / l \ll 1$, outra fórmula assintótica diz que:

$$
\omega^{2} \simeq 2(n+\epsilon) \frac{d c^{2}}{d r}
$$

Tal equação descreve parábolas no plano $k-\omega$, que corresponde as curvas observadas na figura 1.4 .

Os modos-g são diferentes dos modos-p, como pode-se ver na figura 1.2, pois estão todos aprisionados no Sol abaixo de $r=0,75 R$, que trata-se da base da zona de convecção solar. Isso ocorre pois as camadas de convecção instáveis não suportam oscilações de flutuabilidade. Relações assintóticas como as vistas anteriormente mostram que modos-g de baixo $l$ possuem períodos que são uniformemente espaçados, analogamente à separação uniforme de frequências dos modos-p.

A equação de movimento estudada não descreve outra classe de modos de oscilação, os modos-f ou fundamentais, com $\Psi=0$. Essencialmente, tratam-se de ondas de gravidade de superfície, com a amplitude de deslocamento proporcional a $\exp [-k(R-r)]$, e relação de dispersão $\omega^{2}=g k$. Tais modos são normalmente classificados com $n=0$.

As autofrequências calculadas para os modos-g e modos-p podem ser vistas na figura 1.4. Como os modos-p não ficam presos se suas frequências forem superiores à máxima frequência de acústica de corte (próximo a superfície solar), e as frequências monotonicamente aumentam $n$ e $l$, conclui-se que existe um número finito de modos-p aprisionados no interior solar, aproximadamente 10 milhões. Observacionalmente, sabemos que uma boa 


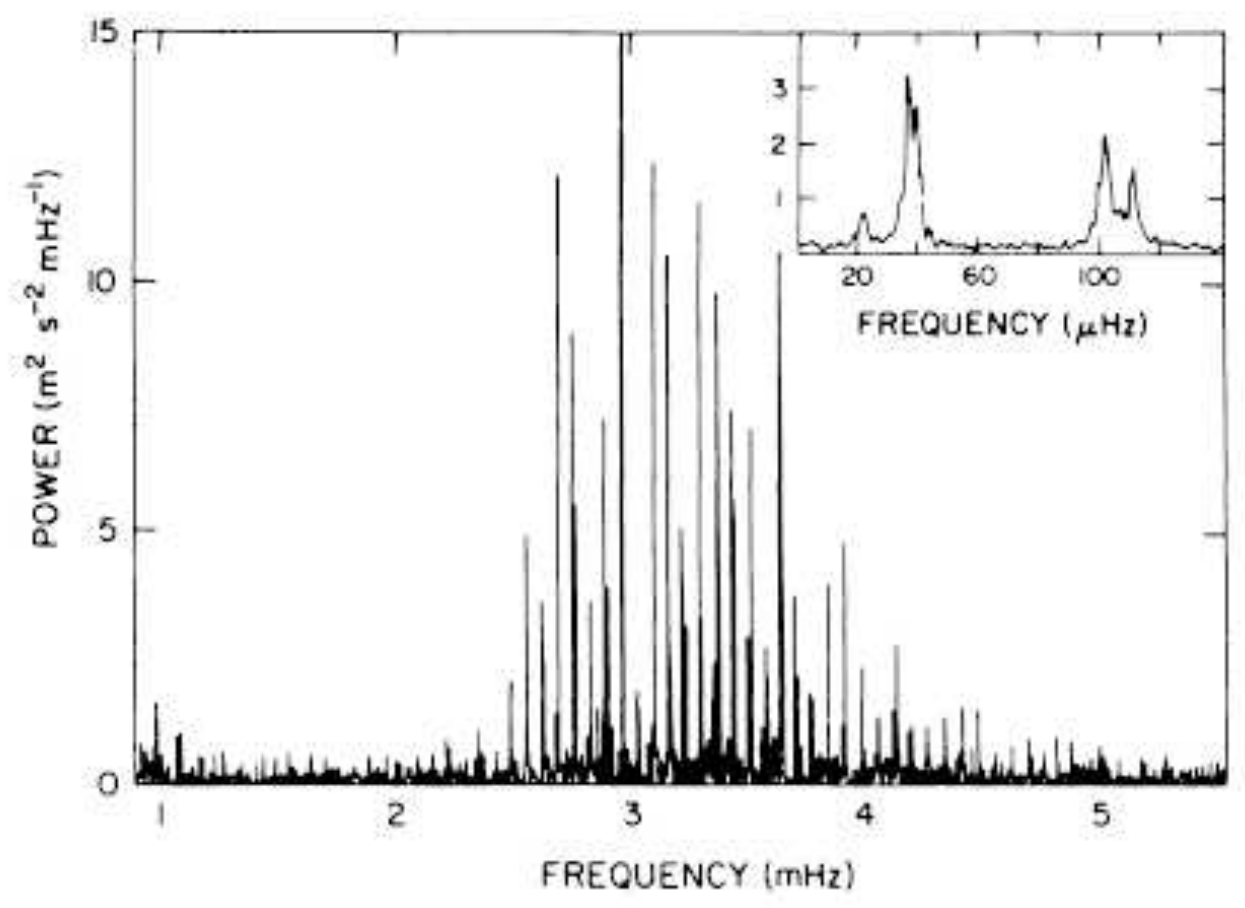

Figura 1.3: Espectro de frequências para modos p de baixo $l$. O destaque é um diagrama de frequências superpostas, com período de repetição $136 \mu \mathrm{Hz}$, demonstrando o espaçamento regular previsto pela teoria assintótica. Figura de Libbrecht (1988). 
fração desses modos, aqueles com frequências entre 1 e $5 \mathrm{mHz}$, são excitados até amplitudes observáveis.
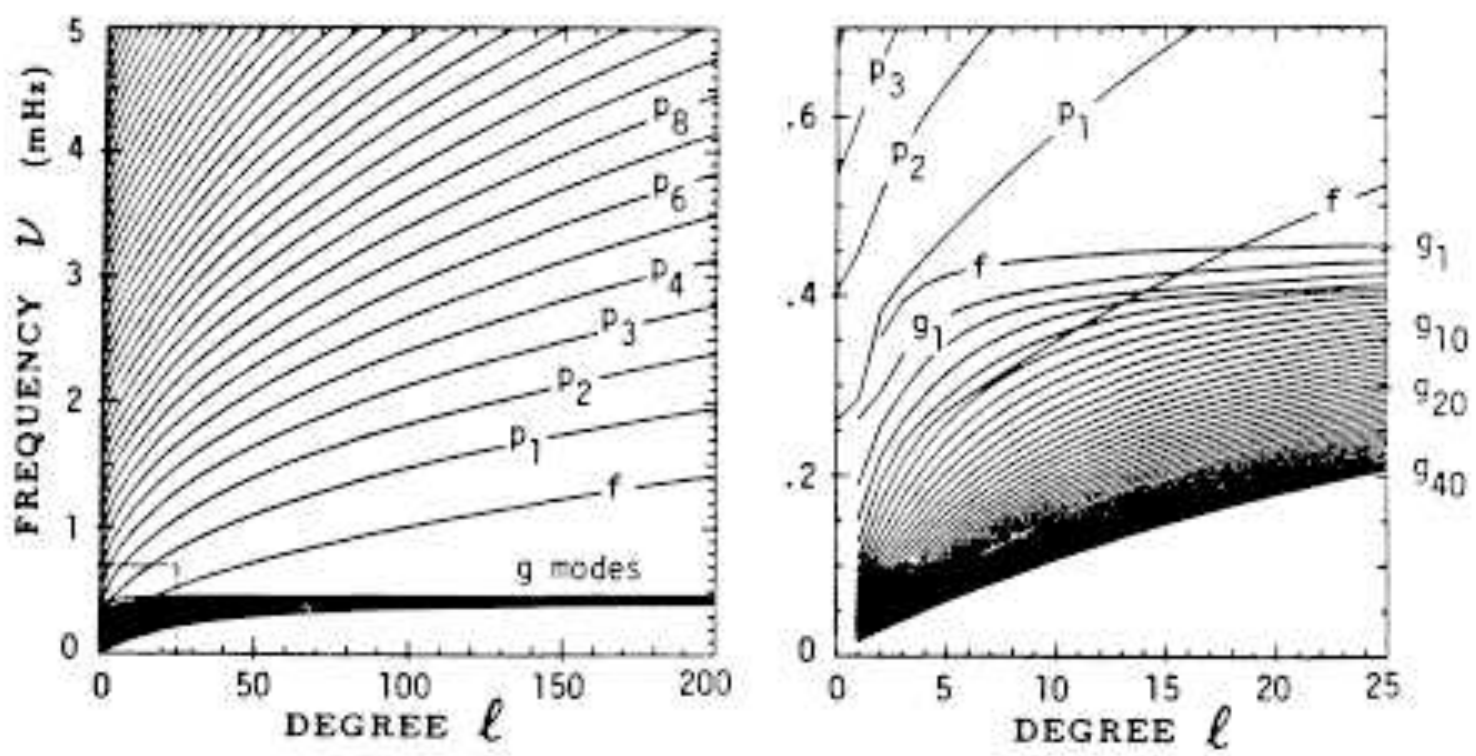

Figura 1.4: Autofrequências em função do grau $l$, computadas para um modelo solar normal. Alguns valores da ordem radial $n$ estão indicados. A partir de modelo de Dalsgaard (2003).

\subsection{Efeitos de rotação}

Assumimos até agora que não existem campos de velocidade no modelo de equilíbrio. Isso é sempre falso para objetos como o Sol, que está em rotação. Em particular, a rotação superficial observada depende da latitude, implicando na existência de campos de velocidade. Além disso, outros campos de velocidade de larga escala, como aqueles causados por convecção, podem ter um efeito nos modos. Dessa forma, é necessário investigar tais efeitos. Além de seu interesse intrínseco, o principal propósito de tais estudos é obviamente estar apto a sondar os campos de velocidade a partir das propriedades observadas das oscilações.

É fácil de notar, a partir de argumentos geométricos, que a rotação pode afetar as frequências observadas. Assumindo que a velocidade angular $\Omega$ é uniforme, e considere uma oscilação com frequência $\omega_{0}$, independente de $m$, no referencial que gira com a estrela. Introduzimos um sistema de coordenadas nesse referencial, com coordenadas $\left(r^{\prime}, \theta^{\prime}, \phi^{\prime}\right)$ relacionados as coordenadas $(r, \theta, \phi)$ em um referencial inercial por 


$$
\left(r^{\prime}, \theta^{\prime}, \phi^{\prime}\right)=(r, \theta, \phi-\Omega t)
$$

Sabemos que no referencial de rotação as perturbações dependem de $\phi^{\prime}$ e $t$ como $\cos \left(m \phi^{\prime}-\omega_{0} t\right)$. Assim, a dependência no referencial inercial é $\cos \left(m \phi-\omega_{m} t\right)$, onde

$$
\omega_{m}=\omega_{0}+m \Omega .
$$

Dessa forma, um obervador no referencial inercial encontra que a frequência divide-se (em inglês, split) uniformemente de acordo com $m$.

Esta descrição entretanto é incompleta. Mesmo no caso da rotação uniforme, os efeitos da força de Coriolis devem ser levados em consideração no referencial de rotação, contribuindo para a separação (splitting) das frequências (Cowling and Newing 1949; Ledoux 1949). Ainda mais, em geral a velocidade angular é uma função $\Omega(r, \theta)$ da posição. No entanto, como mostrado abaixo, o efeito da força de Coriolis é quase sempre pequeno e a equação 1.26 é aproximadamente correta se $\Omega$ é substituído por uma média conveniente da velocidade angular dependente da posição.

Para chegar em uma expressão válida para qualquer lei de rotação é conveniente considerar primeiro o caso ainda mais geral de um campo de velocidades estacionário arbitrário de uma estrela.

\subsubsection{Efeito de velocidades de larga escala nas frequências de oscilação}

Assumiremos que a estrutura de equilíbrio é estacionária, de forma que todas as derivadas temporais desaparecem. Mesmo com essa hipótese, a determinação da estrutura de equilíbrio é um problema não-trivial, devido a distorção causada por campos de velocidade (como por exemplo efeitos de centrífuga em uma estrela em rotação). Entretanto, assumimos que a velocidade $\mathbf{v}_{0}$ no estado de equilíbrio é suficientemente pequena para que termos quadráticos em $\mathbf{v}_{0}$ possam ser ignorados. Assim, a equação da continuidade resulta em

$$
\operatorname{div}\left(\rho_{0} \mathbf{v}_{0}\right)=0
$$

Além disso, devido ao corte de termos de ordem $|\mathbf{v}|^{2}$, as equações de movimento reduzem-se a 


$$
0=-\nabla p_{0}+\rho_{0} \mathbf{g}_{0}
$$

Substituimos a força por unidade de massa $\mathbf{f}$ pela aceleração gravitacional $\mathbf{g}$. Dessa forma, não há mudanças na equação de equilíbrio hidrostático. No caso solar, a razão entre a força centrífuga negligenciada e a gravidade na superfície é da ordem de $2 \times 10^{-5}$ e portanto o erro na equação 1.28 é de fato pequeno.

A velocidade em um dado ponto do espaço pode ser escrita como

$$
\mathbf{v}=\mathbf{v}_{0}+\mathbf{v}^{\prime}
$$

onde $\mathbf{v}^{\prime}$ é a perturbação de velocidade Euleriana. O deslocamento $\delta r$ deve ser determinado relativo ao fluido em equilíbrio em movimento, relacionado a perturbação de velocidade por

$$
\frac{\mathrm{d} \delta \mathbf{r}}{\mathrm{d} t}=\delta \mathbf{v}=\mathbf{v}^{\prime}+(\delta \mathbf{r} \cdot \nabla) \mathbf{v}_{0}
$$

Aqui, $\delta \mathbf{v}$ é a perturbação de velocidade Lagrangiana, e d/dt é a derivada temporal material,

$$
\frac{\mathrm{d} \delta \mathbf{r}}{\mathrm{d} t}=\frac{\partial \delta \mathbf{r}}{\partial t}+\left(\mathbf{v}_{0} \cdot \nabla\right) \delta \mathbf{r} .
$$

Contrastando com o caso de velocidade nula, as derivadas temporais material e local das perturbações agora são diferentes.

A equação de continuidade perturbada pode ser escrita como

$$
0=\frac{\partial \rho^{\prime}}{\partial t}+\operatorname{div}\left(\rho^{\prime} \mathbf{v}_{0}+\rho_{0} \mathbf{v}^{\prime}\right)=\frac{\partial}{\partial t}\left[\rho^{\prime}+\operatorname{div}\left(\rho_{0} \delta \mathbf{r}\right)\right]+\operatorname{div} \rho^{\prime} \mathbf{v}_{0}+\rho_{0}\left[\left(\mathbf{v}_{0} \cdot \nabla\right) \delta \mathbf{r}-(\delta \mathbf{r} \cdot \nabla) \mathbf{v}_{0}\right]
$$

usando as equações 1.30 e 1.31. Isso pode ser reduzido com a equação 1.27 para

$$
\frac{\partial A}{\partial t}+\operatorname{div}\left(A \mathbf{v}_{0}\right)=0
$$

onde

$$
A=\rho^{\prime}+\operatorname{div}\left(\rho_{0} \delta \mathbf{r}\right)
$$


Usando novamente a equação 1.27 , reescrever como

$$
\rho_{0} \frac{\mathrm{d}}{\mathrm{d} t}\left(\frac{A}{\rho_{0}}\right)=0
$$

de onde conclui-se que $A=0$.

Para obter a equação de momento perturbado, partimos da equação de movimento

$$
\rho \frac{\mathrm{d} \mathbf{v}}{\mathrm{d} t}=-\nabla p+\rho \mathbf{f},
$$

e do fato de que a perturbação Lagrangiana e derivada temporal material comutam,

$$
\rho \frac{\mathrm{d}}{\mathrm{d} t}(\delta \psi)=\delta\left(\frac{\mathrm{d} \psi}{\mathrm{d} t}\right)
$$

para qualquer quantidade $\psi$, obtemos

$$
\rho_{0} \frac{\mathrm{d} \delta \mathbf{v}}{\mathrm{d} t}=\delta\left(-\nabla p+\rho \mathbf{g}=-\nabla p^{\prime}+\rho_{0} \mathbf{g}^{\prime}+\rho^{\prime} \mathbf{g}_{0}\right.
$$

usando a equação 1.28. Alternativamente, podemos escrever com a equação 1.30 como

$$
\rho_{0} \frac{\mathrm{d}^{2} \delta \mathbf{r}}{\mathrm{d} t^{2}}=-\nabla p^{\prime}+\rho_{0} \mathbf{g}^{\prime}+\rho^{\prime} \mathbf{g}_{0}
$$

ou, usando a equação 1.31 e ignorando o termo quadrático em $\mathbf{v}_{0}$, temos

$$
\rho_{0} \frac{\mathrm{d}^{2} \delta \mathbf{r}}{\mathrm{d} t^{2}}+2 \rho_{0}\left(\mathbf{v}_{0} \cdot \nabla\right)\left(\frac{\partial \delta \mathbf{r}}{\partial t}\right)=-\nabla p^{\prime}+\rho_{0} \mathbf{g}^{\prime}+\rho^{\prime} \mathbf{g}_{0}
$$

Finalmente, devido a propriedade comutativa da equação 1.37, encontramos que a equação de energia perturbada continua válida. Portanto, para esse nível de acurácia, a única mudança nas equações de perturbação é a inclusão do termo na primeira derivada temporal de $\delta \mathbf{r}$ na equação 1.40 .

Como a estrutura de equilíbrio é independente do tempo, ainda podemos separar a dependência temporal como $\exp (-i \omega t)$. Usando, por simplicidade, os mesmos símbolos para as funções de amplitude nessa separação, obtemos para as equações de movimento

$$
\omega^{2} \rho_{0} \delta \mathbf{r}-2 i \omega \rho_{0}\left(\mathbf{v}_{0} \cdot \nabla\right)(\delta r)=-\nabla p^{\prime}+\rho_{0} \mathbf{g}^{\prime}+\rho^{\prime} \mathbf{g}_{0}
$$

Aqui o termo em $\mathbf{v}_{0}$ é uma pequena perturbação. Dessa forma podemos investigar seu efeito por meio de uma análise perturbativa, e escrevemos a equação 1.41 como 


$$
\omega^{2} \delta \mathbf{r}=F(\delta \mathbf{r})+\delta F(\delta \mathbf{r})
$$

onde

$$
\delta F(\delta \mathbf{r})=-2 i \omega\left(\mathbf{v}_{0} \cdot \nabla\right) \delta \mathbf{r} .
$$

\subsubsection{Splittings de rotação}

Splittings rotacionais tem sido utilizados, utilizando técnicas de inversão, para determinar a rotação interna das estrelas. O exemplo de maior sucesso é o próprio Sol, para o qual o perfil de rotação interna é conhecido de forma precisa devido às inversões heliossísmicas (Thompson et al. 1996).

No domínio da teoria perturbativa, splittings rotacionais correspondem à correção de primeira ordem em $\Omega$ (frequência rotacional) para a frequência de oscilação $\omega_{n, l, m}$. Nesse caso, a aceleração de Coriolis $(2 \Omega \times v)$ domina, e o termo de correção na frequência pode ser escrito como

$$
\omega_{1, m}=\int_{0}^{R} \int_{0}^{\pi} K_{m}(r, \theta) \Omega(r, \theta) \mathrm{d} \theta \mathrm{d} r
$$

onde $K_{m}(r, \theta)$ é o kernel do splitting rotacional, e $R$ o raio estelar. Usamos esta expressão para definir o splitting generalizado $S_{m}$ como

$$
S_{m}=\frac{\omega_{1, m}-\omega_{1,-m}}{2 m}
$$

Por simplicidade, assumiremos aqui rotação shellular, i.e., $\Omega(r)=\Omega_{s}\left[1+\eta_{0}(r)\right]$, para que o splitting torne-se independente de $m$, e seu kernel possa ser escrito como

$$
K(r)=\frac{\xi_{r}^{2}-2 \xi_{r} \xi_{h}+(\Lambda-1) \xi_{h}^{2}}{\xi_{r}^{2}+\Lambda \xi_{h}^{2}} r^{2} \rho_{0}
$$

onde $\xi_{r}$ e $\xi_{h}$ correspondem às componentes radial e horizontal da autofunção. $\rho_{0}$ é a densidade da estrela (não-perturbada), $r$ a distância radial, e $\Lambda=l(l+1)$. O denominador desta equação é conhecido geralmente como inércia do modo. Quando a rotação é assumida uniforme, o splitting rotacional é simplificado para 


$$
S=\Omega \int_{0}^{R} K(r) \mathrm{d} r
$$

Para rotação shellular, o splitting rotacional pode ser escrito na forma dada por Suárez et al. (2006), como

$$
S=m \Omega_{s}\left(C_{L}-1-J_{0}\right)
$$

onde $C_{L}$ é a constante de Ledoux, e $J_{0}$ é uma integral dependente de $\eta$ (nula para rotação uniforme), definida por

$$
J_{0}=\frac{1}{I_{0}} \int_{0}^{R} \eta_{0}(r)\left[y_{01}^{2}+\Lambda z_{01}^{2}-2 y_{01} z_{01}-z_{01}^{2}\right] \rho_{0} r^{4} \mathrm{~d} r .
$$

com $I_{0}$ sendo a inércia do modo previamente definida na equação 1.46.

\subsubsection{Assimetrias do splitting rotacional}

Normalmente observa-se que o splitting rotacional não é perfeitamente simétrico (com respeito a seus modos axisimétricos). Matematicamente, assimetrias do splitting podem ser definidas, em sua forma generalizada, como

$$
A_{m}=\omega_{-m}+\omega_{+m}-2 \omega_{0}
$$

Usando álgebra simples, pode-se mostrar que as assimetrias do splitting são dependentes somentes de termos em segunda ordem de $\Omega$, particularmente

$$
A_{m}=m^{2} X_{2} \frac{\Omega_{s}^{2}}{\omega_{0}}
$$

onde expressões para $X_{2}$ (na notação de Saio) podem ser encontradas em Suárez et al. (2006) ou Goupil (2009). Então, é possível construir o kernel para as assimetrias do splitting, $K_{2}$ tais que

$$
A_{m}=m^{2} \int_{0}^{R} \Omega^{2}(r) K_{2}(r) r^{2} \rho_{0} \mathrm{~d} r
$$

que é implicitamente dependente do perfil de rotação $\eta_{0}$.

No capítulo 4, examinaremos $K_{2}$ em detalhes para estrelas quentes com rotação moderada. Para fazer isso, será necessário investigar o comportamento de $A_{m}$ para diferentes 
tipos de modo e sua sensibilidade a variações do perfil de rotação em diferentes zonas do interior estelar. 


\section{Capítulo 2}

\section{Observações de estrelas quentes com satélite CoRoT}

\subsection{Introdução sobre o satélite CoRoT, long/short runs}

CoRoT (COnvection ROtation and planetary Transits, see for example Boisnard \& Auvergne 2004) é uma missão espacial liderada pelo Centre National d'Études Spatiales (CNES) em conjunto com a agência espacial européia (ESA) e outros parceiros internacionais, dentre os quais o Brasil. Trata-se de um satélite astrofísico dedicado à sismologia e a detecção de trânsitos de planetas extra-solares.

O satélite foi lançado em dezembro de 2006, em uma órbita polar inercial e uma altitude de $897 \mathrm{~km}$. O instrumento consiste primariamente de um telescópio de $\phi=27 \mathrm{~cm}$. Seu programa científico abarca três objetivos:

1. um programa central de sismologia (SISMO), que concentra-se no estudo sísmico de aproximadamente 10 estrelas brilhantes $(6<V<9)$ selecionadas por campo de observação. As observações são feitas com um cadência de 32 segundos que permite uma análise de frequências bastante precisa;

2. um programa central de exoplanetas (EXO) que busca encontrar exoplanetas orbitando aproximadamente 12000 estrelas fracas $(11.5<V<16)$ por campo. O sampling dos dados de EXO possui uma cadência de 512 segundos; e

3. um programa adicional (AP) que estuda algumas centenas de estrelas variáveis fracas $(11.5<V<16)$ no mesmo campo de EXO.

Dentro dos dados do programa central de exoplanetas existem estrelas quentes dentre as quais várias serão novos pulsadores, enriquecendo as estatísticas do fenômeno de pulsações 
não-radiais.

O satélite aponta alternadamente para duas regiões fixas no céu, centradas em 18h50 (região do 'centro' galáctico) e 06h50 ('anticentro'), por cerca de 150 dias cada. Propusemos a observação de uma série de estrelas Be localizadas na região do centro, priorizando alvos mais fracos $(12<V<16)$, que poderão ser observados com os CCDs do programa exoplanetário.

\subsection{Classificação espectral de alvos nos campos de observação do satélite}

\subsubsection{Primeiro anúncio de oportunidade}

Obtivemos os dados no Observatório do Pico dos Dias (LNA), em dois períodos distintos. Primeiro, entre os dias 17 e 19 de julho de 2003, e depois, nas noites de 7 e 8 de junho de 2004. As observações foram feitas com o telescópio Perkin-Elmer de 1,6m de diâmetro, com um espectrógrafo Cassegrain com rede de 900 linhas/mm. Foram cobertos comprimentos de onda entre 374 e 526 nm, que é a região de classificação clássica (onde se encontram as linhas mais utilizadas para a classificação espectral).

As reduções foram feitas utilizando o procedimento padrão (sem calibração em fluxo) com o pacote IRAF (Barnes 1993, Massey 1997 e Massey et al. 1992).

Todos os alvos escolhidos para as observações em 2003 acabaram sendo descartados por estarem longe dos alvos primários do satélite (estrelas FGK que constituem o programa científico primário de sismologia), que na época ainda não haviam sido claramente definidos. Nas observações feitas em 2004 tal problema não existiu. As estrelas analizadas podem ser vistas na tabela 2.4 .

Os espectros resultantes das estrelas foram utilizados para identificar todas as linhas espectrais possíveis, e suas respectivas intensidades e larguras. Dessa forma, foi possível determinar alguns parâmetros físicos fundamentais: tipo espectral, classe de luminosidade e velocidade de rotação.

\section{Classificação espectral}

A classificação espectral das estrelas consistiu em determinar suas temperaturas efetivas, ou seja, separá-las entre O9 e A0, e determinar sua classe de luminosidade, de acordo 
com a tabela 2.2 .

O procedimento seguiu o esquema tradicional de Morgan \& Keenan (1973), ou seja, comparação dos espectros retificados dos alvos de interesse com aqueles de estrelas-padrão obtidos nas mesmas condições de observação. Por tal razão também observamos padrões com tipos espectrais variando entre $\mathrm{O} 9$ e A4 e classes de luminosidade entre I e V.

Utilizamos os critérios apresentados por Yamashita et al. (1977), Walborn \& Fitzpatrick (1990) e Steele et al. (1999). Todas as estrelas foram classificadas sem conhecimento prévio de classificações pré-existentes (disponíveis em CDS-Simbad, por exemplo).

Velocidades de rotação

Valores de $v \sin i$, a velocidade de rotação equatorial multiplicada pelo seno do ângulo de inclinação do eixo de rotação, podem ser determinados medindo-se o alargamento Doppler de linhas espectrais. Ajustou-se perfis gaussianos a 5 linhas do HeI, localizadas em 4026, 4143, 4387, 4471 e $4922 \AA$. A largura a meia altura (full width at half maximum, FWHM) resultante foi calibrada com $v \sin i$ utilizando o critério de Slettebak et al. (1975).

O procedimento foi feito com sucesso para a maioria das estrelas, com exceção daquelas onde a contaminação por alguma absorção ou emissão de outra natureza fosse muito evidente.

\section{Resultados}

Os espectros reduzidos e retificados dos alvos analisados no cone central do satélite podem ser vistos na figura 2.1 .

Os resultados obtidos de classificação espectral e velocidades de rotação estão na tabela 2.3. Uma comparação com os tipos espectrais determinados anteriormente (tabela 2.4) mostra que os resultados são compatíveis. Informações sobre velocidade de rotação são bem mais escassas e não estavam disponíveis nos catálogos de VizieR para as estrelas observadas, impossibilitando comparações.

\subsubsection{Segundo anúncio de oportunidade}

Tendo em vista agora o Anúncio de Oportunidade para o segundo ano do satélite, priorizamos novamente as estrelas localizadas ao redor de $18 \mathrm{~h} 50$ ('centro'), com magnitudes 


\begin{tabular}{lll}
\hline \hline objeto & FK5 (2000) & MK \\
\hline [KW97] 36-36 & $191539.1-011741$ & Ow. \\
BD-02 4786 & $185603.5-023731$ & - \\
CDS 1053 & $191502.1+013407$ & - \\
ALS 10047 & $185520.0-002131$ & - \\
QT Ser & $183104.5+043737$ & B5 \\
HD 177880 & $190635.1-014026$ & B5V \\
BD-05 4885 & $190532.8-002929$ & - \\
[M81] I-733 & $192054.1+004624$ & - \\
BD+04 3760 & $182903.6+040355$ & B8 \\
BD+03 3736 & $183156.0+035031$ & B8 \\
\hline
\end{tabular}

Tabela 2.1 - Relação das estrelas observadas com telescópio de 1,6m do LNA no campo centro do satélite. O tipo espectral foi obtido de CDS-Simbad.

\begin{tabular}{ll}
\hline \hline Classe & Tipo de estrela \\
\hline Ia & Supergigantes luminosas \\
Ib & Supergigantes menos luminosas \\
II & Gigantes brilhantes \\
III & Gigantes normais \\
IV & Subgigantes \\
V & Estrelas da sequência principal (anãs) \\
\hline
\end{tabular}

Tabela 2.2 - Classes de luminosidade de Morgan-Keenan. 

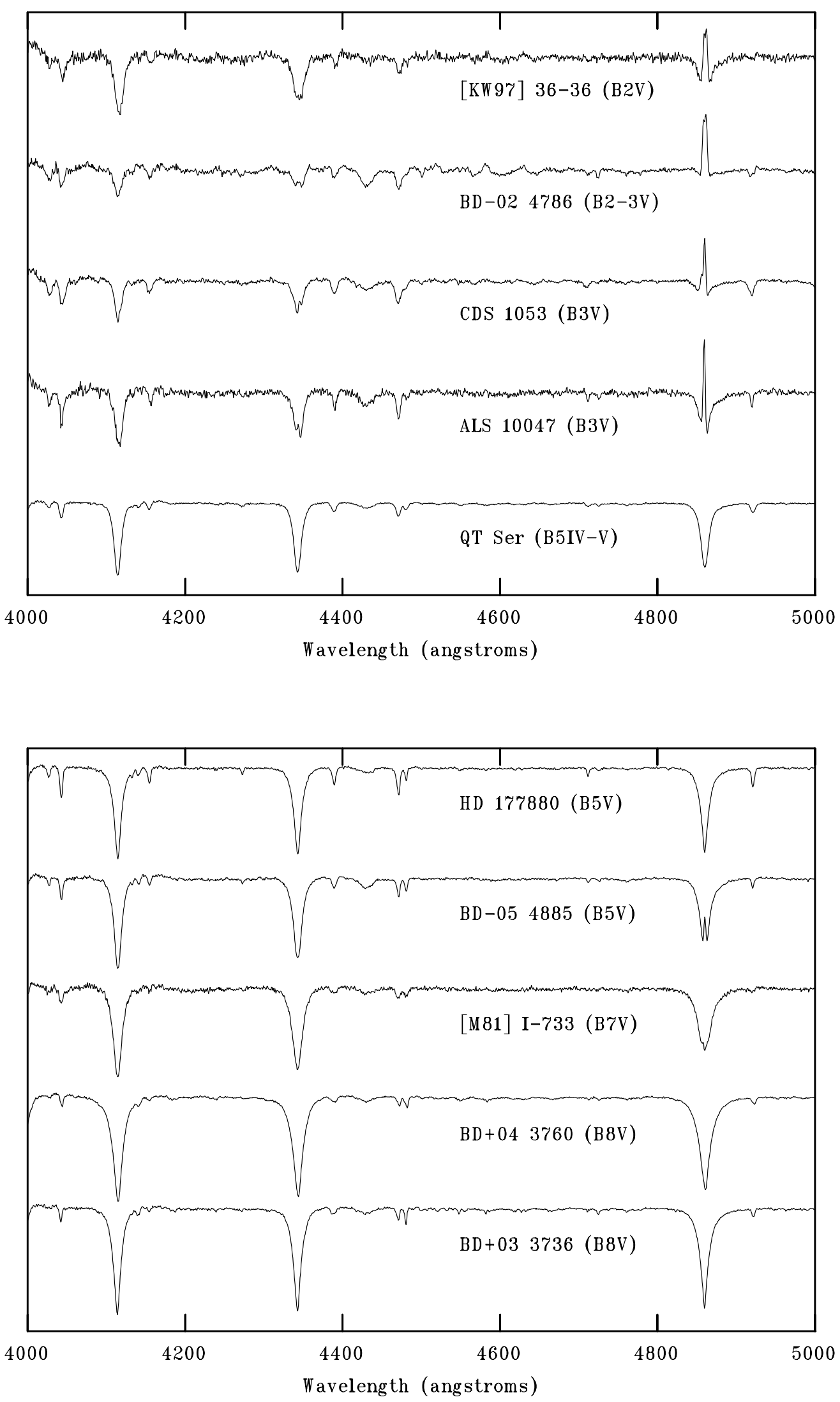

Figura 2.1: Espectros retificados dos alvos observados na região centro de observação de CoRoT. De cima para baixo, a temperatura efetiva é decrescente. 


\begin{tabular}{lll}
\hline \hline objeto & $v \sin i(\mathrm{~km} / \mathrm{s})$ & $\mathrm{MK}$ \\
\hline [KW97] 36-36 & $*$ & B2V \\
BD-02 4786 & $*$ & B2-3V \\
CDS 1053 & $306(12)$ & B3V \\
ALS 10047 & $192(42)$ & B3V \\
QT Ser & $210(15)$ & B5IV-V \\
HD 177880 & $126(8)$ & B5V \\
BD-05 4885 & $123(27)$ & B5V \\
[M81] I-733 & $207(44)$ & B7V \\
BD+04 3760 & $204(38)$ & B8V \\
BD+03 3736 & $159(64)$ & B8V \\
\hline
\end{tabular}

Tabela 2.3 - Resultados obtidos para velocidades de rotação e classificação espectral das estrelas analisadas. (*) Estrelas que apresentam emissão em linhas de HeI.

$12<V<16$, e que deveriam ter sido observadas durante a 'long-run' de 2007, sendo assim estrelas próximas aos possíveis alvos principais.

Dados foram obtidos no Observatório do Pico dos Dias (LNA), na noite de 20 de agosto de 2005. As observações foram feitas com o telescópio Perkin \& Elmers de 1,6m de diâmetro, com um espectrógrafo Cassegrain com rede de 900 linhas/mm. Foram cobertos comprimentos de onda entre 400 e 500 nm (região de classificação espectral clássica). As reduções foram feitas utilizando o procedimento padrão (sem calibração em fluxo) com o pacote IRAF.

As condições climáticas no observatório (umidade, céu fechado, chuvas) impediram a observação de todos os alvos programados. Apenas três estrelas observadas (tabela 2.4) possuem razão $\mathrm{S} / \mathrm{N}$ suficiente $(\sim 50)$ para possibilitar a determinação de parâmetros físicos.

HBHA 204-06 e HBHA 703-04 não apresentaram linhas de emissão de Hidrogênio ou Hélio, e foram portanto descartadas para observação com CoRoT. Problemas operacionais do satélite acabaram impedindo que curvas de luz dos alvos classificados fossem obtidas. Além disso, quase todos os alvos possuem $v \sin i$ muito maior do que o adequado para a análise perturbativa que descreveremos a seguir. Dessa forma, neste trabalho concentramo- 


\begin{tabular}{lllll}
\hline \hline objeto & FK5 (2000) & V & MK \\
\hline HBHA 204-06 & $190949+035850$ & 12.5 & \\
HBHA 703-04 & $185803+080301$ & 12.5 & B \\
HBHA 703-07 & $190828+070642$ & 12.1 & \\
\hline
\end{tabular}

Tabela 2.4 - Relação das estrelas observadas com telescópio de 1,6m (OPD) no campo centro do satélite. Informações retiradas de CDS/Simbad.

nos no estudo de outras estrelas quentes com rotação moderada que possuem frequências observadas e parâmetros físicos determinados na literatura. 
Capítulo 3

\section{Modelos de pulsações de estrelas quentes}

\subsection{Modelo de estrutura estelar CESAM}

Como um problema analítico, as equações hidrodinâmicas básicas foram resolvidas para os casos adiabático e não-adiabático, desprezando efeitos de rotação e campos magnéticos (Unno et al., 1989), ou para o caso adiabático utilizando rotação (Christensen-Dalsgaard, 2003). Como um problema numérico, existem implementações já utilizadas para estrelas de tipo $\delta$ Scuti que utilizamos como ponto de partida. Ambas foram desenvolvidas por pesquisadores do Instituto de Astrofísica de Andalucía (IAA), Espanha, e partem do cálculo de modelos estelares em equilíbrio com o código de evolução CESAM (Morel, 1997). Tratase de um conjunto de programas e rotinas que realizam cálculos de evolução estelar em equilíbrio quasi-estático e unidimensional, incluindo atmosfera. A familiarização com o programa se deu com o cálculo de modelos de estrelas B/Be típicos.

A solução do equilíbrio quasi-estático é feita por um método de collocation baseado em aproximações polinomiais projetadas em uma base de B-splines. Isso permite cálculos estáveis e robustos, e uma exata restituição da solução - não somente em pontos da grade - até para as variáveis descontínuas. Outras de suas vantagens são o monitoramento por apenas um parâmetro de acurácia e sua melhora por superconvergência. Para modelospadrões, a evolução da composição química é resolvida por esquemas estáveis rígidos de ordem (até) quatro. Em zonas convectivas, mistura e evolução química são calculadas simultaneamente. A solução da equação de difusão emprega o esquema de elementos finitos de Galerkin, e a mistura de elementos químicos é então feita por forte difusão turbulenta.

Dentro das limitações devidas à degenerescência eletrônica, CESAM permite o cálculo evolutivo quasi-estático de modelos estelares enquanto a hipótese de equilíbrio quasi- 
estático permanece válida, ou seja, até a exaustão do oxigênio no núcleo. A estrutura modular de CESAM facilita as escolhas dentre diversos formalismos físicos: equação de estado (EOS, equation of state), convecção, opacidades, coeficientes de difusão, etc ... Muitas redes nucleares e misturas iniciais estão disponíveis que permitem optimizar a a descrição física de acordo com o tipo de modelo e fase evolucionária de interesse. CESAM foi feito de forma a facilitar a implementação das grandezas na forma mais próxima de seu formalismo físico. Para resolver as equações diferenciais, o programa transforma-as para um "espaço numérico".

Unidades e valores de constantes físicas. CESAM utiliza unidades em cgs, exceto pela massa, raio e luminosidade, expressos em unidades solares. Dois conjuntos de constantes fundamentais físicas são implementados. Para cada cálculo, um desses conjuntos é apontado como fonte única das constantes físicas fundamentais. Outras constantes são iniciadas localmente, por exemplo, excessos de massa, na rotina que calcula as taxas de reações termonucleares.

Arquivos de entrada. Apenas um arquivo de entrada, o "input data file" (IDF) é necessário. O IDF é lido antes de iniciar os cálculos, e contém todos os requisitos necessários para os cálculos:

- parâmetros físicos: massa, composição química, parâmetro de comprimento de mistura, etc ...

- parâmetros numéricos: número máximo de camadas, tipo de precisão, etc ...

- critérios para interromper o cálculo: idade a ser alcançada, valor da abundância de hidrogênio no centro, etc ...

- nomes e localização dos arquivos de dados externos contendo EOS e dados de opacidade, nomes de rotinas físicas a serem utilizadas, nome do modelo, do conjunto de unidades a ser utilizado, etc ...

Arquivos de saída. Para cada passo temporal, um arquivo "return binary file" (RBF) é criado. Ele contém todos os dados necessários para inicializar ou continuar o cálculo computacional. Todos os arquivos RBF podem ser arquivados, ou simplesmente o último a ser criado. A partir desse arquivo, "output data files" (ODFs) podem ser criados. Três foram 
especialmente criados para pesquisas adiabáticas, não-adiabáticas e inversão astrossísmica. O primeiro de tais arquivos servirá de entrada para o cálculo das pulsações adiabáticas que serão feitas em seguida.

Tipos de precisão. Para optimizar os cálculos, conjuntos de parâmetros chamados "réglages" são fixados de acordo com o tipo de modelos a serem calculados, e seu uso subsequente. Os mais utilizados foram:

- "realistic precision" (precisão realista) para evolução padrão, compatível com observações astrossísmicas em terra.

- "super precision" (super precisão) usada quando um nível de acurácia muito alto é necessário.

- "solar accuracy" (precisão solar) próxima da super precisão, mas especialmente feita para investigações sísmicas; o número de camadas do último modelo é aumentado até seu valor máximo. Precisão mais compatível com aquela esperada pelo satélite CoRoT.

Naturalmente, quanto maior a acurácia esperada, maior o tempo computacional gasto pelo programa.

\subsubsection{Procedimento}

Inicialização. Ao rodar o programa, o arquivo IDF é lido. Então, a composição química é iniciada de acordo com a mistura inicial e com os isótopos utilizados pela rede nuclear envolvida. As taxas de reações nucleares são tabeladas em intervalos de temperatura relevantes. As taxas são computadas usando as fórmulas de, ou Caughlan \& Fowler (1988), ou compilações NACRE de Angulo et al. (1999). Em seguida, a evolução em si começa, a partir de um de dois cenários:

- começa de um modelo inicial de idade zero (ZAMS). Tal modelo, tendo as características requeridas, é deduzido de um modelo a partir de um RBF, ou de um modelo padrão fornecido pelo programa; ou

- busca um cálculo anterior, ou seja, a entrada é o arquivo RBF de uma evolução em curso. 
Um modelo de ZAMS com composição química homogênea não é uma realidade física, dado que a fusão nuclear não ocorre em equilíbrio. Entretanto, é uma forma conveniente e rápida de, após alguns passos temporais, alcançar um modelo próximo ao fim da fase pré-sequência principal. Diversos modelos iniciais (de diferentes massas) de ZAMS em ASCII são fornecidos pelo programa.

Evolução. O número de camadas é atualizado. Então, levando overshootings em consideração, os limites entre as zonas radiativas e convectivas são localizados. A velocidade angular $(\beta)$ e a composição química são atualizados. A seguir, as equações de equilíbrio quasi-estático para o interior estelar são solucionadas. O processo repete-se até a convergência.

O controle do passo temporal é primeiramente baseado na acurácia local obtida para a integração numérica dos elementos químicos de interesse relevante, e, em seguida, na limitação das mudanças relativas de hélio na estrela como um todo. No caso de divergência de qualquer algoritmo iterativo, o passo temporal é cortado pela metade.

Critérios de parada. De acordo com as instruções do usuários determinados no IDF, os cálculos podem ser interrompidos:

- quando a idade esperada é atingida.

- quando a temperatura central atinge um valor específico.

- quando a abundância central de hidrogênio atinge um valor específico.

- quando há exaustão de hidrogênio no centro.

- quando a extensão do núcleo de hélio atinge um determinado tamanho.

- quando a temperatura efetiva ultrapassa um determinado valor.

- na ignição do ciclo $3 \alpha$.

- na ignição do ciclo do carbono.

- na ignição do clico do oxigênio.

Para a maioria dos tipos de precisão, o último passo temporal é ajustado de forma a corresponder a condição de parada requerida. 


\subsubsection{Métodos numéricos}

Escolha de variáveis. Para a integração numérica das equações de estrutura estelar, a forma Lagrangiana é a mais conveniente visto que a discretização da massa é expressada diretamente. Entretanto, ela apresenta uma singularidade no centro, e o núcleo precisa ser integrado separadamente. A forma Euleriana das equações não sofre de tal inconveniência, mas conforme o raio estelar varia com respeito ao tempo, sobra um contorno livre. Com as variáveis Lagrangianas: $\mu \equiv M^{2 / 3}, R^{2}, L^{2 / 3}$, a singularidade central desaparece (Morel, 1997) e não há necessidade de um tratamento especial para o núcleo ( $M$ é a massa, $L$ a luminosidade e $R$ o raio). Para manter a consistência, espécies químicas são escritas como função de $M^{2 / 3}$. A pressão, $P$, e a temperatura, $T$, são expressos em logaritmos, $(\xi=\ln P$, $\eta=\ln T$ ), visto que são grandezas que se alteram por mais de seis magnitudes do centro até a fotosfera da estrela.

Resolvendo as equações diferenciais. Os parâmetros desconhecidos são aproximados por polinômios por pedaços de ordem definida de acordo com a precisão requerida, sendo as mais utilizadas as ordens 1 (linear) e 2 (parabólica). Para o modelamento estelar essa representação flexível está bem adaptada à presença de descontinuidades resultante da mistura nas zonas convectivas.

Para os cálculos, os polinômios por pedaços são projetados em uma base linear local de B-splines normalizados (De Boor, 1978; Schumacker, 1981). Isso permite encontrar a solução exata em qualquer posição.

Refinamento de malha. Um refinamento de malha (mesh refinement) automático é implementado. No tempo $t$, as posições dos pontos da malha $n(t)$ são estabelecidas ao preencher a condição que, de um ponto da grade ao outro, o pulo de uma "função de repartição" estritamente monótona $Q(\mu, t)$ é igual a uma "constante de repartição" $C(t)$ (Eggleton, 1971). As localizações dos pontos da grade, $\mu_{i}, i=1, \ldots, n$, conhecidos no início das computações, satisfaz:

$$
Q\left(\mu_{i+1}, t\right)-Q\left(\mu_{i}, t\right) \equiv C(t) \quad i=1, \ldots, n-1 .
$$

A escolha de $Q(\mu, t)$ é baseada em um conhecimento a priori do comportamento da solução. Para cada $t$, define-se uma função "índice" $q(\mu, t)$ mapeando $\left[0, \mu_{\mathrm{b}}\right]$ em $[1, n]$. O índice 1 corresponde ao centro, e o índice $n$ à superfície, ou seja, $\mu_{\mathrm{b}}=M_{\mathrm{ext}}^{\frac{2}{3}}$. Logo, a 
integração é feita em uma rede equidistante. Em termos da derivada de $Q$ com respeito a q, temos da equação 3.1 que:

$$
\left(\frac{\partial \psi}{\partial q}\right)_{t}=0, \quad \operatorname{com} \quad \psi(t) \equiv\left(\frac{\partial Q}{\partial q}\right)_{t}
$$

A mudança de variáveis $\mu \rightarrow q(\mu, t)$ :

$$
\psi(t)=\theta\left(\frac{\partial \mu}{\partial q}\right)_{t}, \quad \operatorname{com} \quad \theta(\mu, t) \equiv\left(\frac{\partial Q}{\partial \mu}\right)_{t}
$$

é calculada a partir da forma analítica de $Q(\mu, t)$. Existem mais duas incógnitas: $\psi(t)$ e $\mu(q, t)$. Elas formam uma sistema de equações diferenciais de primeira ordem com condições de contorno:

$$
\left(\frac{\partial \mu}{\partial q}\right)_{t}=\frac{\psi}{\theta}, \quad\left(\frac{\partial \psi}{\partial q}\right)_{t}=0, \quad \operatorname{com} \quad \begin{cases}q=1, & \mu=0 \\ q=n, & \mu=\mu_{\mathrm{b}}\end{cases}
$$

Escrevemos finalmente as equações de estrutura interna com respeito a $q$, e resolvemos o sistema para uma grade equidistante, que permite optimizações numéricas.

\subsubsection{Rotação}

Assumindo simetria esférica, podemos considerar a rotação com CESAM. Com velocidade angular diferente de zero, a aceleração centrífuga média afeta a gravidade local. No modelo inicial, uma rotação rígida é assumida. A velocidade angular inicial pode ser lida do IDF em diferentes unidades:

- $\mathrm{rad} / \mathrm{s}$.

- $\mathrm{km} / \mathrm{s}$, correspondente a velocidade de rotação superficial (parte externa) da estrela. Como o raio externo depende da gravidade externa, o modelo inicial precisa ser adaptado iterativamente para alcançar a velocidade externa requerida.

- dias, correspondendo ao período de rotação.

Para rotação sem difusão de momento angular, diversas opções são disponíveis:

- sem rotação, a velocidade angular inicial também precisa ser zero. 
- rotação de corpo rígido com velocidade angular mantida em seu valor inicial.

- rotação rígida com momento angular globalmente conservado. A velocidade angular muda com respeito ao tempo, de acordo com mudanças estruturais.

- a velocidade angular muda de acordo com a conservação do momento angular local. Rotação não-rígida, salvo nas zonas mistas.

Neste trabalho, efeitos de rotação nos modelos de equilíbrio sao levados em conta de forma simplificada, incluindo a contribuiç ao esfericamente simétrica da aceleração centrífuga por meio de uma gravidade efetiva $g_{\text {eff }}=g-A_{c}(r)$, onde $g$ é a gravidade local e $A_{c}(r)$ representa a componente radial da aceleração centrífuga (Kippenhahn \& Weigert 1990). Também assumiremos rotação de corpo rígido, com momento angular total globalmente conservado.

\subsubsection{Convecção}

Dois formalismos principais para o cálculo do gradiente de temperatura em zonas de convecção são disponibilizados: o formalismo padrão de comprimento de mistura de BöhmVitense (1958), considerado com a profundidade óptica da bolha convectiva, e o formalismo de Canuto \& Mazzitelli (1991). Em ambos, o comprimento de mistura é um parâmetro livre estabelecido pelo IDF.

Overshooting abaixo e/ou acima das zonas convectivas pode ser considerado. Os parâmetros de overshooting também são livres e lidos na IDF. Nas regiões atingidas, o gradiente de temperatura é determinado a partir do gradiente adiabático ou do gradiente radiativo. As zonas convectivas e suas extensões por overshooting são homogeneizadas. Tratamento completo de semi-convecção não é implementado por CESAM.

\subsubsection{Equação de estado e opacidade}

Quatro equações de estado (EOS) analíticas são implementadas em CESAM. As mais úteis são EFF (Eggleton et al., 1973) e CEFF (Christensen-Dalsgaard \& Dappen, 1992). EOS numéricas também são disponibilizadas. As tabelas MHD (Mihalas et al., 1988) e as tabelas OPAL 1993 e OPAL 2001 são utilizadas com o esquema de interpolação OPAL para tabelas com $Z=0.01$ e $Z=0.02$. 
Tabelas de opacidade OPAL 1996 são implementadas, com valores de baixa temperatura de Kurucz. As razões entre as abundâncias dos elementos pesados são fixadas em seus valores iniciais, independente de mudanças devidas às reações nucleares e difusão. Apenas os neutrinos gerados pelas reações nucleares são levados em consideração, assumindo que podem escapar livremente da estrela. Para valores de temperatura acima de $T \geq 710^{7} \mathrm{~K} \simeq$ 7Kev, o plasma é completamente ionizado, portanto a opacidade média de Rosseland é reduzida a espalhamento Compton por elétrons livres (Cox \& Giuli, 1968).

\subsection{Modelo de cálculo de frequências de oscilação FILOU}

Os modelos em equilíbrio calculados com CESAM serviram como entrada para o cálculo dos espectros teóricos de oscilação das estrelas, utilizando o código FILOU (Suárez 2002), cuja principal característica é o cálculo de frequências de oscilação radiais e não-radiais na presença de rotação. Originalmente desenvolvido por F. Tran Mihn e L. Léon no Observatoire de Paris-Meudon (Tran Mihn \& Léon, 1995), o código passou por diversas modificações e melhoras de forma a corrigir as frequências de oscilação por efeitos de rotação (Suárez, 2002). Em particular, FILOU calcula (de maneira perturbativa) frequências de oscilações adiabáticas corrigidas por efeitos de rotação (até segunda ordem na taxa de rotação) incluindo efeitos de degenerescência próxima. Além disso, FILOU trabalha com rotação uniforme ou perfis de rotação diferencial radial (rotação shellular), característica que torna o código único.

Embora FILOU esteja optimizado para o estudo do comportamento oscilatório de pulsadores clássicos de massa intermediária (estrelas $\delta$ Scuti e $\gamma$ Doradus), o código é de uso universal. Do ponto de vista numérico, FILOU resolve conjuntos de equações diferenciais ordinárias (ODE) em um problema de valor de contorno (BVP) utilizando um método que combina Galerkine e B-Splines que realça a precisão numérica com que as frequências de oscilação são calculadas. Além disso, é possível modificar facilmente inúmeros parâmetros numéricos de forma a ajustar o cálculo de forma óptima para o modelo requerido, o que torna FILOU um código muito versátil. 


\subsubsection{Oscilações adiabáticas}

FILOU é baseado principalmente nas equações de oscilação e suas perturbações desenvolvidas por Dziembowski \& Goode (1992) e Soufi et al. (1998). A notação seguida é similar àquela utilizada por muitos outros códigos de oscilação, mas adaptada ao desenvolvimento teórico considerado. O código pode funcionar com diferentes esquemas de cálculos, quais sejam, sem rotação, aproximação de Cowling, e rotação (uniforme e diferencial). No caso mais geral, i.e., na presença de rotação shellular, oscilações são calculadas a partir de modelos de pseudo-rotação, construídos modificando as equações de estrutura estelar de forma a incluir a contribuição simétrica esférica da aceleração centrífuga, por meio de uma gravidade efetiva $g_{\text {eff }}=g-A_{c}(r)$, onde $g$ e $A_{c}(r)$ são o componente da gravidade local e a aceleração centrífuga, respectivamente. Os efeitos de componentes não-esféricos da deformação da estrela são incluídos por uma perturbação nas equações de oscilação. Por exemplo, a perturbação da densidade média $\rho_{0}$ de um modelo de pseudo-rotação é considerada na forma $\rho_{2}=p_{22}(r) P_{2}(\cos \theta)$, onde $p_{22}(r)$ é definido em Suárez et al. (2006)

Além disso, quando degenerescência próxima é levada em consideração, as autofrequências e autofunções de um modo próximo de degenerescência assumem a forma:

$$
\begin{gathered}
\omega^{\mathrm{d}}=\tilde{\omega}_{0}+\tilde{\omega}_{1}+\tilde{\omega}_{2} \\
\xi=\sum_{j=a, b} \alpha_{j}\left(\xi_{0, j}+\xi_{1, j}\right)
\end{gathered}
$$

onde $\tilde{\omega}_{0}=\left(\tilde{\omega}_{0, a}+\tilde{\omega}_{0, b}\right) / 2$ e $\alpha_{j}$ representa os coeficientes de combinação linear entre os dois modos considerados degenerados. Índices $a$ e $b$ representam dois modos rotacionalmente acoplados quaisquer. Correções de primeira e segunda ordem na autofrequência são representadas por $\tilde{\omega}_{1}$ e $\tilde{\omega}_{2}$ respectivamente. $\xi_{0, j}$ e $\xi_{1, j}$ são as autofunções não-perturbada e de primeira ordem.

\subsubsection{Estrutura e esquema do cálculo}

FILOU é composto por um programa principal e alguns módulos escritos em C e duas sub-rotinas escritas em FORTRAN $(77,95)$, que lêem os dados de entrada dos modelos de 
equilíbrio e calcula os efeitos de degenerescência próxima para os modos rotacionalmente acoplados.

O cálculo das frequências de oscilação radiais e não-radiais de uma dada cavidade ressonante (modelo de equilíbrio de entrada) é dividido em três passos sequenciais: first, frequências de oscilação de ordem zero (autovalor $\omega_{0}$ ) são computadas. Em seguida, para cada autofrequência, as correções de frequência de segunda ordem correspondentes (sem incluir efeitos de degenerescência) são calculadas. Por fim, o código seleciona, seguindo certas regras (Suárez et al. 2006), os modos acoplados rotacionalmente (somente pares de modos acoplados são selecionados) e calcula os termos de correção de degenerescência próxima correspondentes.

Arquivos de entrada e saída

Os inputs de FILOU são essencialmente algumas quantidades físicas lidas do modelo de equilíbrio (saída de CESAM), e alguns parâmetros iniciais escolhidos pelo usuário em um arquivo de texto (ASCII) e lidos pelo código quando executado. Os parâmetros principais são:

- O arquivo contendo o modelo de equilíbrio.

- O tipo de cálculo computacional. Esta opção permite ao usuário forçar algum tipo de regime de cálculo (por exemplo, aproximação de Cowling, não-rotação, rotação uniforme, rotação diferencial). Da mesma forma, o usuário pode escolher o tipo de arquivo de saída (apenas a lista de frequências, incluir ou não as correções por efeito de rotação, ou efeitos de degenerescência, etc.).

- Tipo de condições de contorno.

- Tipo de atribuição de nós (zeros de $y_{01}$ ou método JCD).

Os arquivos de saída básicos oferecidos por FILOU são uma lista de autofrequências e autofunções. Entretanto, é possível obter arquivos de saída com dados de cálculos intermediários. 
Capítulo 4

\section{Aplicações para estrelas quentes de rotação moderada}

\subsection{Análise de assimetrias em estrelas $\beta$ Cephei}

O estudo da rotação interna de estrelas é uma das principais preocupações da física estelar. A rotação está presente em quase todas as estrelas, e interage com outros processos físicos atuantes do interior estelar. Em particular, entender o transporte do momento angular no interior estelar é crucial para descrever a evolução de forma precisa e correta. Turbulência, circulação meridional, mistura de elementos, efeitos de dínamo devido a presença de campos magnéticos, etc. são alguns dos principais fenômenos e processos afetados pela rotação (ver por exemplo Goupil et al. 2005, Goupil 2009, e Goupil \& Talon 2009).

Hoje em dia, é possível sondar a estrutura interna de estrelas graças a astrossismologia. No que se refere à rotação, progresso tem sido feito, nas últimas décadas, no conhecimento sobre a interação pulsação-rotação. Até agora, este problema tem sido abordado usando técnicas perturbativas como FILOU para computar as oscilações estelares. Tais métodos só são válidos para rotatores lentos e/ou moderados $\left(v_{r o t, s} \leq 120 \mathrm{~km} / \mathrm{s}\right)$. Para rotatores rápidos, a distorção da estrutura estelar devido à força centrífuga é muito grande e invalida as técnicas perturbativas.

Consideramos portanto estrelas com rotação moderada, ou seja, aquelas para as quais os parâmetros $\epsilon=\Omega /\left(G M / R^{3}\right)^{1 / 2}$ e $\mu=\Omega / \nu_{n, l}$ são pequenos: a estrutura estelar não é deformada significativamente pela força centrífuga, e frequências de oscilação são muito maiores que a taxa de rotação angular, respectivamente. Restringimos portanto esse estudo para estrelas em rotação mostrando oscilações em um domínio de frequências de relativa baixa ordem (modos g- e p- baixos, modos mistos), em particular as estrelas massivas do tipo $\beta$ Cephei. 
Além disso, a heterogeneidade dos processos e estruturas internas em interiores estelares são argumentos fortes para assumir rotação não-uniforme. Faz-se necessário portanto levar em consideração possíveis variações (nas direções radial ou angular) do transporte de momento angular, e portanto na forma de seu perfil interno de rotação. Para isso, utilizamos o código de oscilação FILOU, que corrige as frequências de oscilação até efeitos de rotação de segunda ordem (incluindo efeitos de degenerescência próxima) na presença de rotação radial diferencial.

Esta técnica é aplicada para analisar as assimetrias dos splittings de modos devidos à rotação. Em particular, estamos interessados em examinar o comportamento do splitting rotacional e suas assimetrias para diferentes modos (g e p), na presenção de rotação radial diferencial, i.e. buscar entender fisicamente como as variações do perfil de rotação interno afetam as assimetrias. Como visto no capítulo 1, splittings e assimetrias são definidos como:

$$
\begin{gathered}
S_{j}=0.5\left(\omega_{-1, j}+\omega_{+1, j}\right) \\
A_{j}=\omega_{-1, j}+\omega_{+1, j}-2 \omega_{0, j}
\end{gathered}
$$

onde $\omega$ indica a freqüência, $j$ indica um modelo, e $-1,0$ e +1 representam o valor da ordem azimutal $m$.

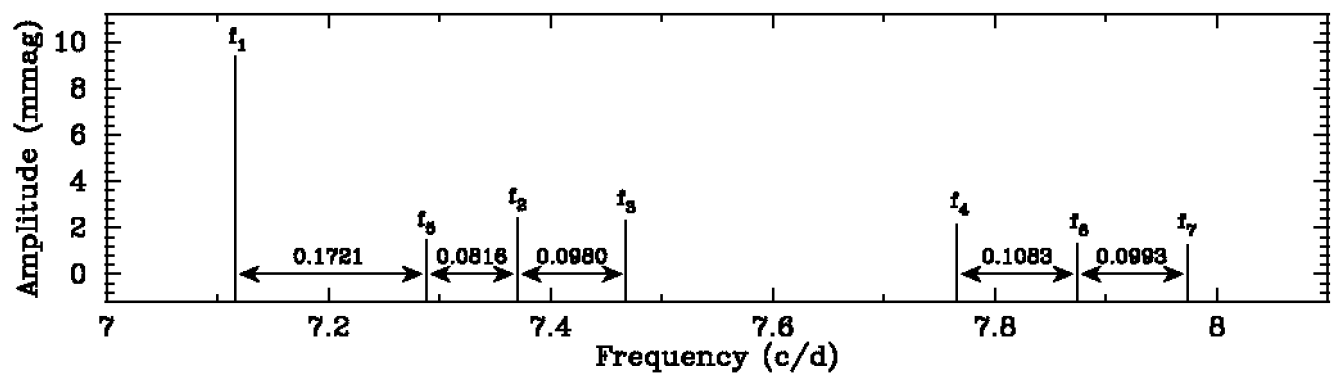

Figura 4.1: Espectro de amplitude esquemático da estrela $\theta$ Oph. As freqüências $f_{4}, f_{6}$ e $f_{7}$ constituem o tripleto do modo $p 1$ (Handler et al. 2005).

O objetivo do trabalho consistiu em melhorar a qualidade de tais modelos de forma a poder cotejá-los com as características observacionais de pulsações não-radiais num processo 
iterativo que conduz à determinação mais precisa dos parâmetros físicos e da estrutura interna de tais estrelas. Em particular, procuramos determinar o perfil radial de rotação no interior dos objetos. Os satélites da geração atual (CoRoT, Kepler, etc...) permitem medir os parâmetros das pulsações não-radiais com grande sensibilidade de detecção e grande poder de resolução de freqüências.

Apresentamos os resultados obtidos a partir de observações fotométricas e espectroscópicas (Handler et al. 2005) da estrela de tipo $\beta$ Cephei $\theta$ Ophiuchi $(v \sin i=29 \pm 7 \mathrm{~km} / \mathrm{s}$, Briquet et al. 2007).

Procedemos primeiro calculando com o código computacional perturbativo existente (FILOU) modelos (tabela 4.1) de uma estrela que reproduzam bem as freqüências centrais e os splittings observados (figuras 4.2 e 4.3).

\begin{tabular}{lllllll}
\hline \hline ov & $T_{\text {eff }}$ & $\log L / L_{\odot}$ & $\bar{\rho}$ & age & $v_{\text {rot }, s}$ & $\nu_{p 1_{0}}$ \\
\hline 0.40 & 4.344 & 3.724 & 0.097 & 22.000 & 20.959 & 92.649 \\
0.44 & 4.343 & 3.735 & 0.092 & 23.000 & 20.647 & 90.594 \\
0.48 & 4.345 & 3.732 & 0.096 & 23.000 & 20.907 & 92.232 \\
\hline
\end{tabular}

Tabela 4.1 - Melhores modelos para a estrela $\theta$ Ophiuchi, todos com $M=8.5 M_{\odot}$. Da esquerda para à direita, ov é o overshooting, $T_{\text {eff }}$ a temperatura efetiva (K em log), $L$ a luminosidade, $\bar{\rho}$ a densidade média (cgs), a idade (em Myr), $v_{r o t, s}$ a velocidade de rotação linear na superfície e $\nu_{p 1_{0}}$ a freqüência do modo $p 1(l=1, m=0)$ em $\mu \mathrm{Hz}$.

\subsubsection{Variação dos perfis de rotação}

Os modelos da tabela 4.1 foram então modificados artificialmente para conseguir diferentes distribuições de suas taxas de rotação interna. Esperamos que as assimetrias sejam muito sensíveis à modificações do perfil de rotação próximas ao núcleo convectivo. Dessa forma, é interessante modificar o perfil de rotação nesta região. Para fazer isso, consideramos três cenários diferentes (figuras 4.4(a), 4.4(b) e 4.4(c)) onde três tipos de variações no perfil de rotação são consideradas.

O primeiro cenário consiste no caso simples de perfis de rotação lineares. Modificamos a freqüência de rotação central do modelo de referência para valores entre $25 \%$ e $100 \%$ de seu valor original, mantendo a freqüência de rotação na superfície inalterada. Como pode ser 


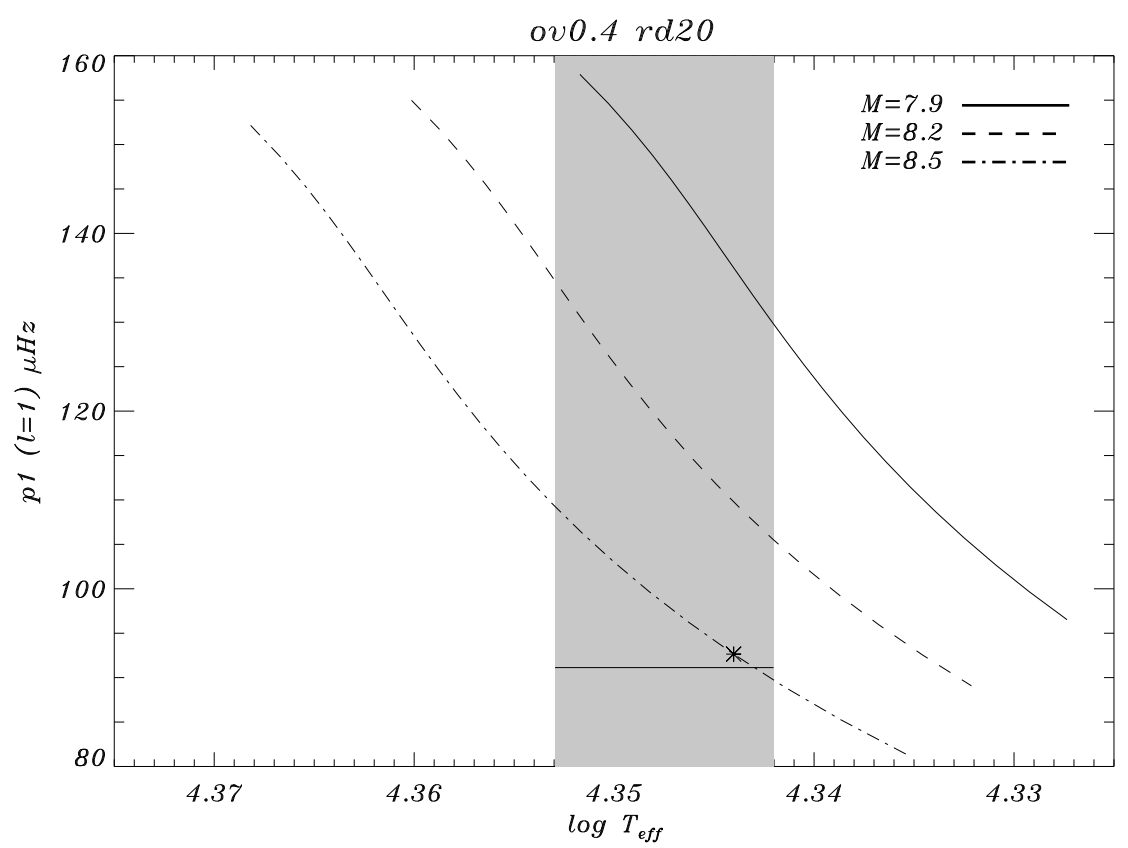

Figura 4.2: Freqüências do modo $p 1(l=1, m=0)$ em $\mu \mathrm{Hz}$ em função da temperatura efetiva para conjuntos de modelos com velocidade de rotação superficial $v_{r o t, s}=20 \mathrm{~km} / \mathrm{s}$ e taxa de overshooting $\alpha=0.40$, para três massas distintas: 7.9, 8.2 e 8.5 massas solares. A largura da linha horizontal representa a incerteza em $T_{\text {eff }}$ de $\theta$ Ophiuchi de acordo com Briquet et al. (2007), e seu valor é igual a freqüência observada $p 1\left(f_{6}\right)$ de Handler et al. (2005). O asterisco marca o modelo mais próximo de $\nu(\mathrm{p} 1, m=0)$ observada. 


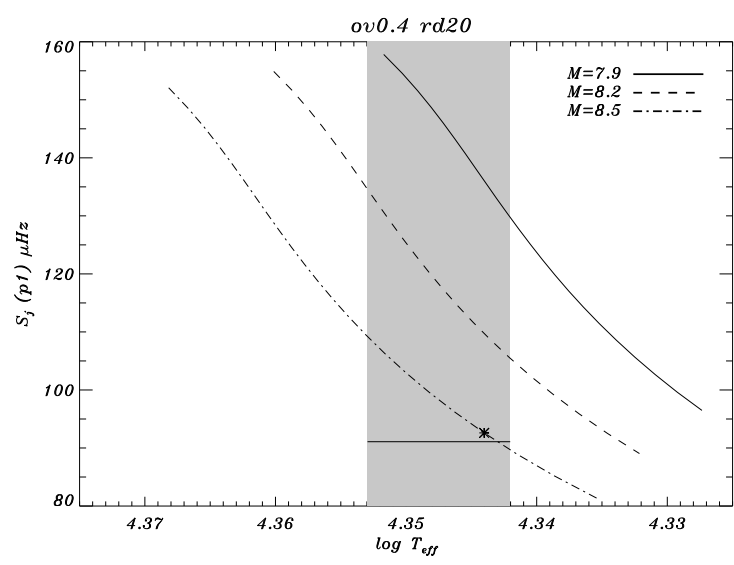

(a)

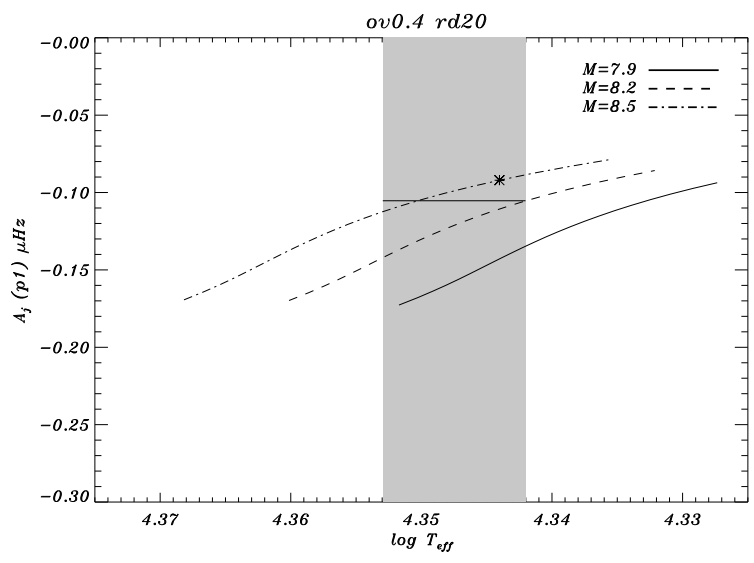

(b)

Figura 4.3: Splittings (a) e assimetrias (b) do modo $p 1(l=1)$ em $\mu \mathrm{Hz}$ como função da temperatura efetiva para uma série de modelos com velocidade de rotação $v_{r o t, s}=20 \mathrm{~km} / \mathrm{s}$ e taxa de overshooting $\alpha=0.40$. A área cinza representa a incerteza na temperatura efetiva $T_{\text {eff }}$ de $\theta$ Ophiuchi e a linha horizontal representa a freqüência $p 1(l=1, m=0)$ observada. O asterisco marca o modelo mais próximo da freqüência observada.

visto na figura 4.4(a), os perfis lineares não apresentam nenhuma descontinuidade entre o núcleo e o envelope (por volta de $r=0.2 R_{\odot}$ no modelo). A princípio isso remove possíveis problemas numéricos devido às descontinuidades (derivadas, pontos de divergência, etc.).

O segundo cenário consiste no uso de perfis shellulares. Como para o modelo original, assumimos rotação uniforme para o núcleo e conservação local do momento angular para o envelope. De fato, os perfis de rotação mostrados na figura 4.4(b) são idênticos ao original em sua região do envelope (região curva), e fixos em uma certa porcentagem do valor original da rotação no núcleo. Estes perfis não evitam o problema da descontinuidade entre o núcleo e o envelope. Além disso, quanto maior é $\nu_{\Omega}$ do núcleo, maior é o seu tamanho. Isso de certa forma reproduz (inversamente) a evolução estelar na seqüência principal assumindo conservação local do momento angular, onde o tamanho do núcleo diminui com o tempo, aumentando a taxa de rotação no centro e diminuindo na superfície.

O terceiro tipo de perfil é uma versão suavizada do perfil de rotação do modelo original. Sua principal característica é, ao contrário dos perfis originais, apresentar uma variação suave de $\nu_{\Omega}$ com o raio, similar ao cenário 1, mas mantendo a forma "shellular" do perfil (ver figura 4.4(c)). Os perfis suavizados são obtidos aproximando ao perfil original polinômios 
de diferentes ordens.

\subsubsection{Kernels do splitting rotacional, assimetrias e termos de segunda ordem}

Com todos os modelos modificados calculado, analisamos em seguida:

1. a variação do kernel de splitting rotacional para os diferentes perfis, o que permite comparar a mudança da energia de modos de pulsação ao longo do raio da estrela. Novamente, vemos quais suas possíveis influências sobre a variação das assimetrias (figuras 4.5, 4.6, 4.7 e 4.8);

2. a variação do valor de termos das equações de perturbação de segunda ordem com os diferentes perfis. Identificamos quais têm mais influência na variação das assimetrias de distintos modos. A comparação é feita com o modelo que possui o perfil de rotação padrão (saída do código de estrutura e evolução estelar, CESAM). Exemplos nas figuras 4.11 e 4.12 .

Seguindo a formulação de Suárez et al. (2006) e suas referências, analisamos o comportamento do kernel de splitting rotacional para os modos $g_{2}, g_{1}, p_{1}$ and $p_{2}(l=1)$ computados dos modelos discutidos nos cenários 1, 2 e 3. Na figura 4.5, comparamos $K\left(g_{2}\right)$ (primeiro painel a partir da esquerda), $K\left(g_{1}\right)$ (segundo painel), $K\left(p_{1}\right)$ (terceiro painel) e $K\left(p_{2}\right)$ (quarto painel) computados para o modelo 1 da tabela 4.1 e seus respectivos modelos com perfis de rotação modificados. Como esperado, a sensibilidade do splitting na região do núcleo $(r / R \sim 0.2)$ é maior para os modos $g$ que para os modos $p$, então, a princípio, qualquer modificação no perfil de rotação nesta região deve ser mais importantes para os primeiros.

Uma vez analisado o comportamento dos kernels do splitting rotacional, calculamos, para cada modelo, as assimetrias $\left(A_{j}\right)$ dos multipletos $g_{2}, g_{1}, p_{1}$ e $p_{2}(l=1)$. As assimetrias estão definidas como na equação 2. As assimetrias computadas são então comparadas com aquelas obtifas para os modelos de referência. Os resultados desta comparação são mostrados nas figuras 4.9 e 4.10 .

Por fim, analisamos como a modificação do perfil interno de rotação altera os coeficientes de segunda ordem $X_{i}$ e $Y_{i}$ conforme definidos no Apêndice B de Suárez et al. (2006). 


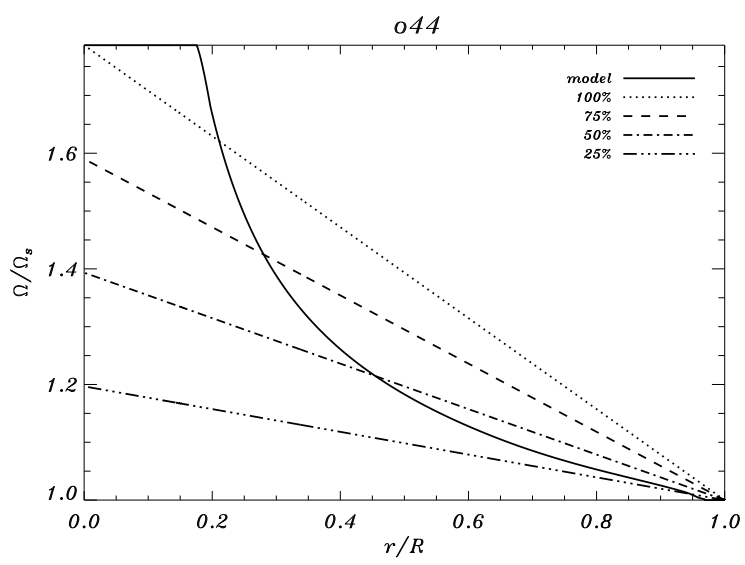

(a)

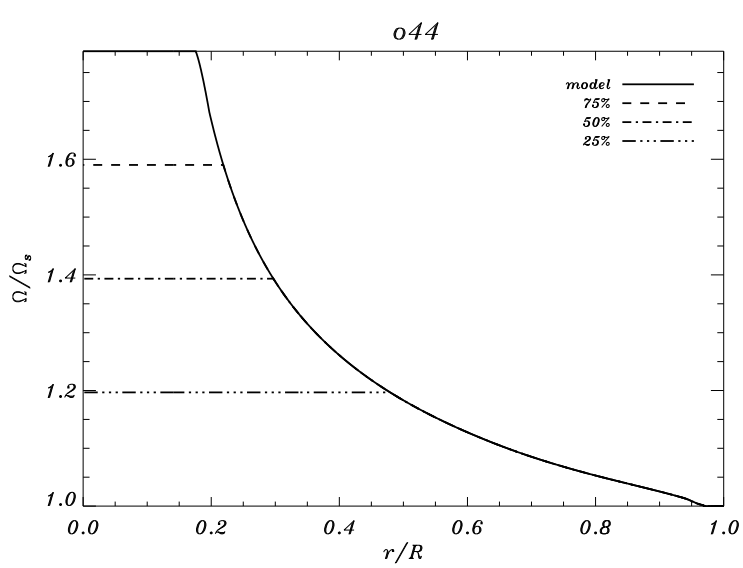

(b)

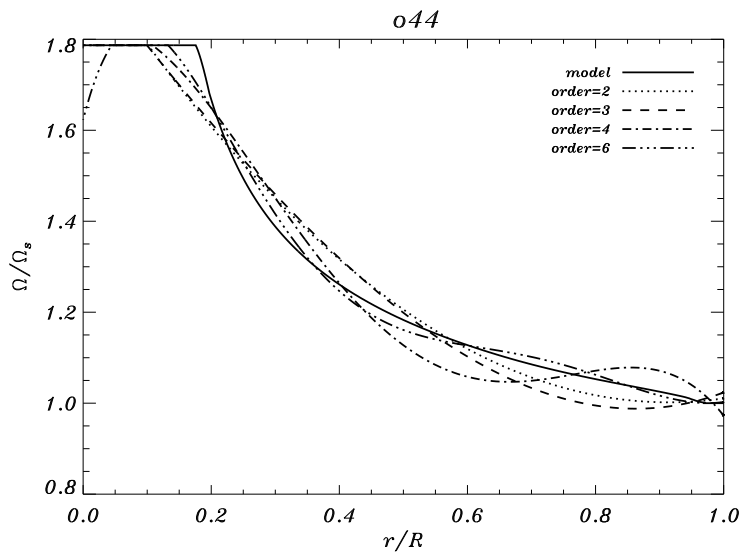

(c)

Figura 4.4: Perfis de rotação modificados do modelo 2 da tabela 4.1, assumindo (a) distribuição radial linear (linhas retas), (b) taxa de rotação central variável (shellular), e (c) ajustes de polinômios de diferentes ordens ao perfil original. A linha cheia mostra o perfil de rotação original para comparação. 
As figuras 4.11 e 4.12 contém as variações, para os diferentes cenários, dos dois termos mais importantes.

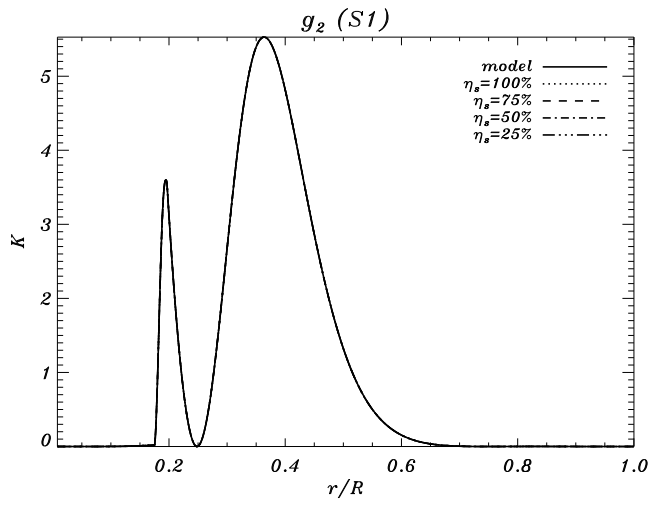

(a)

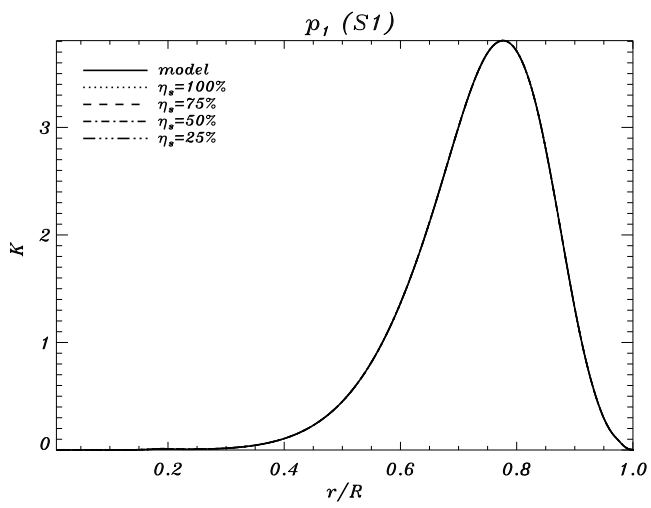

(c)

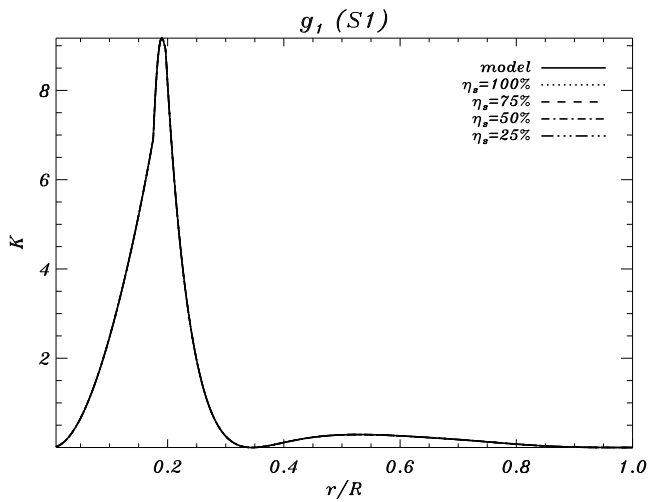

(b)

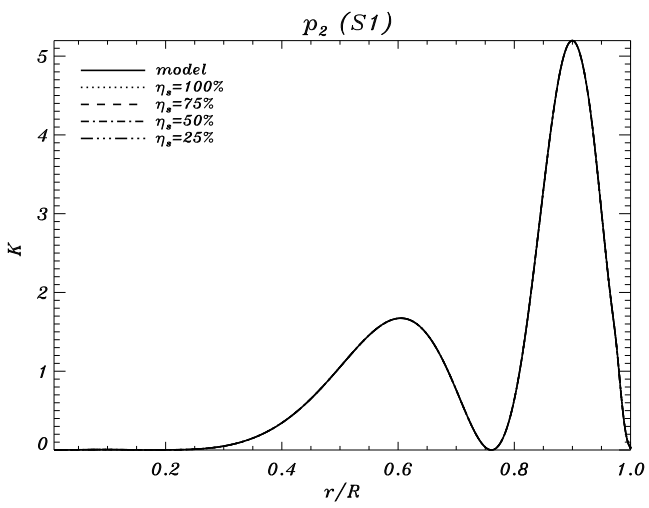

(d)

Figura 4.5: Dependência radial dos kernels para os modos $g 2, g 1, p 1$ e $p 2(l=1)$ calculados a partir dos modelos com perfis de rotação modificados em função da coordenada radial (normalizada em relação ao raio da estrela).

Com tal procedimento, conseguimos:

1. identificar as características do perfil de rotação interna das estrelas quentes, indispensável para fazer modelos mais realistas; e

2. simplificar o problema: refazemos o código de cálculo perturbativo contendo apenas os termos dominantes quanto à sensibilidade à rotação, tornando mais preciso e eficiente o cálculo de pulsações não-radiais para as estrelas estudadas. 


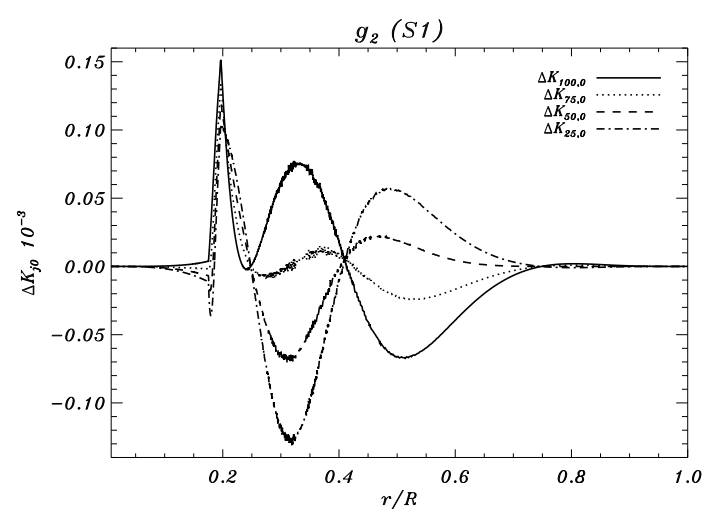

(a)

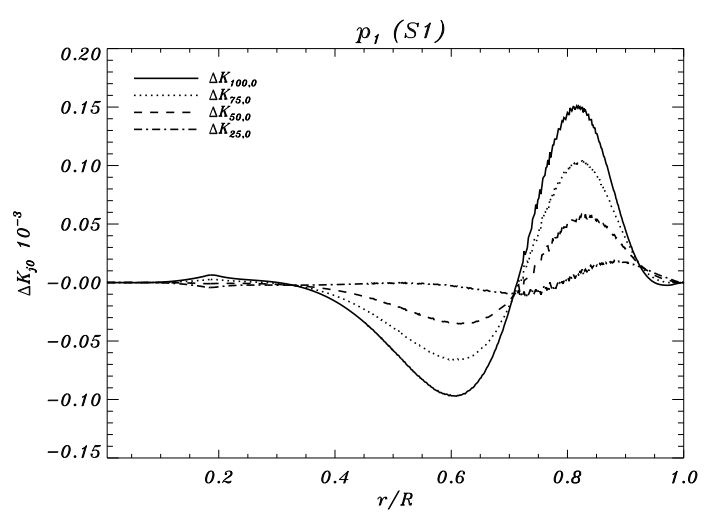

(c)

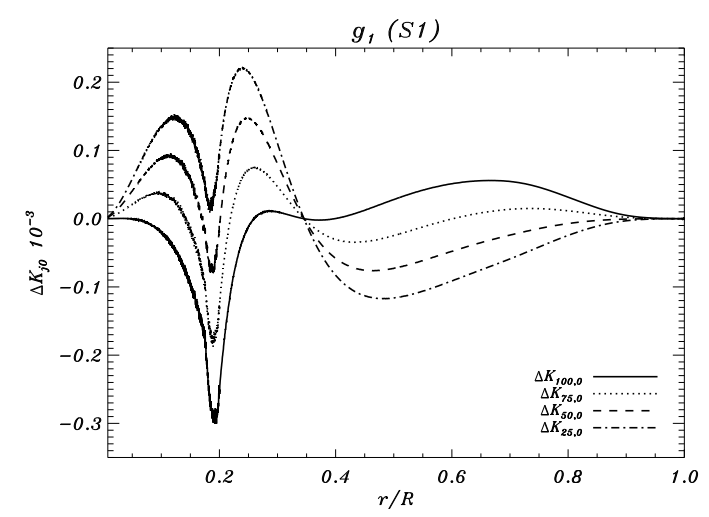

(b)

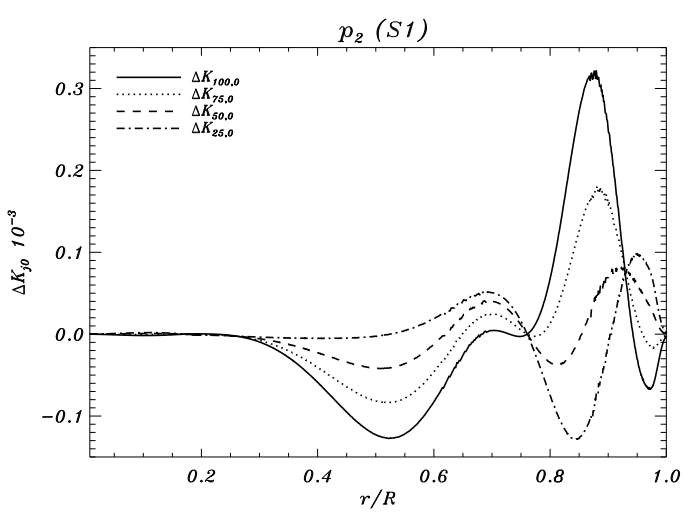

(d)

Figura 4.6: Diferenças absolutas entre os kernels obtidos com modelos com perfis de rotação lineares e o modelo de referência, para os modos $g 2, g 1, p 1$ e $p 2$. Os valores $\Delta K_{i}$ representam a porcentagem da taxa de rotação do núcleo em relação ao modelo de referência. 


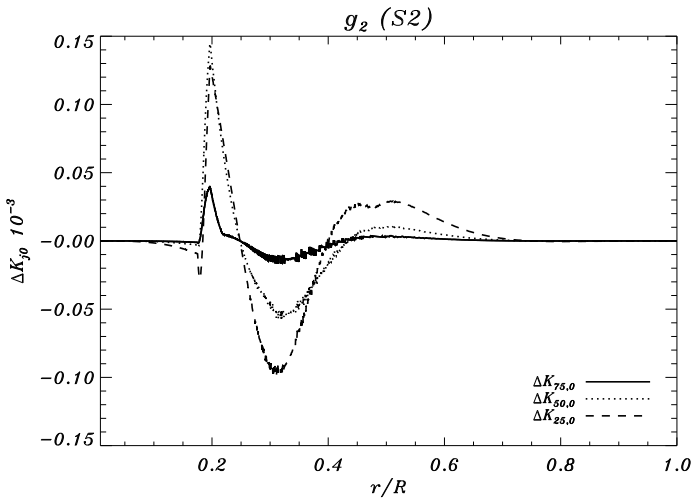

(a)

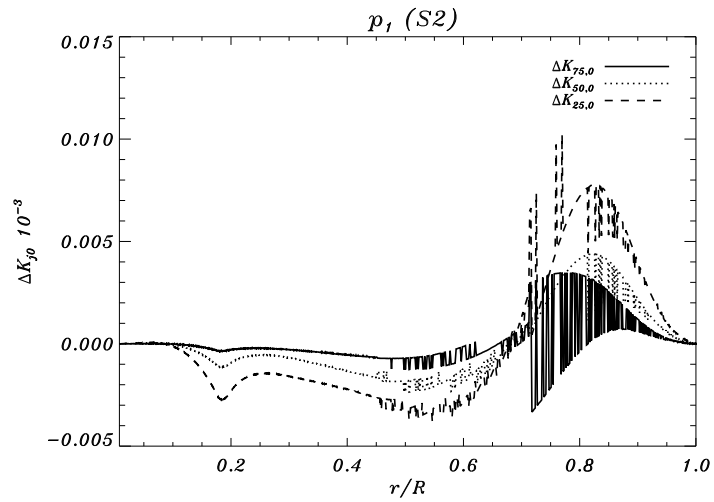

(c)

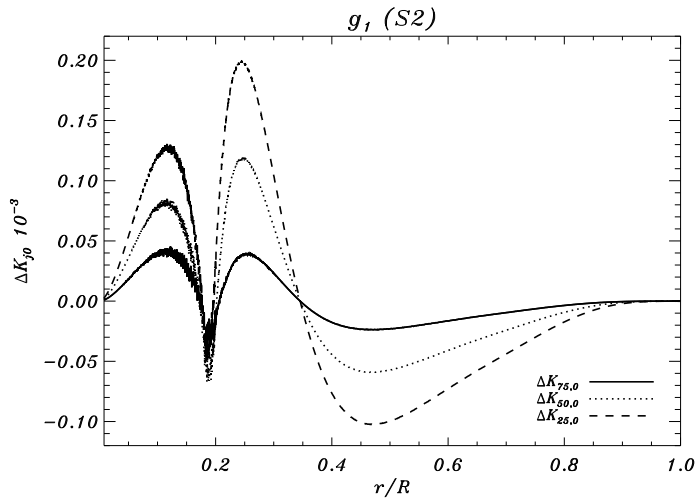

(b)

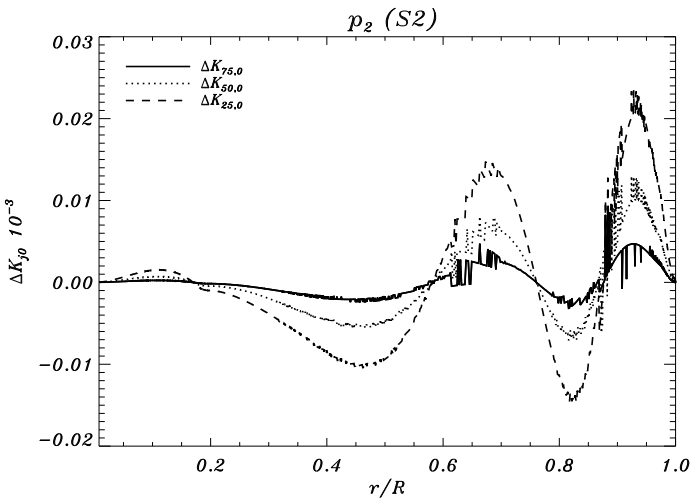

(d)

Figura 4.7: O mesmo que a figura 4.6 para modelos com perfil de rotação "shellular". Os valores de $\Delta K_{i}$ têm significado equivalente. 


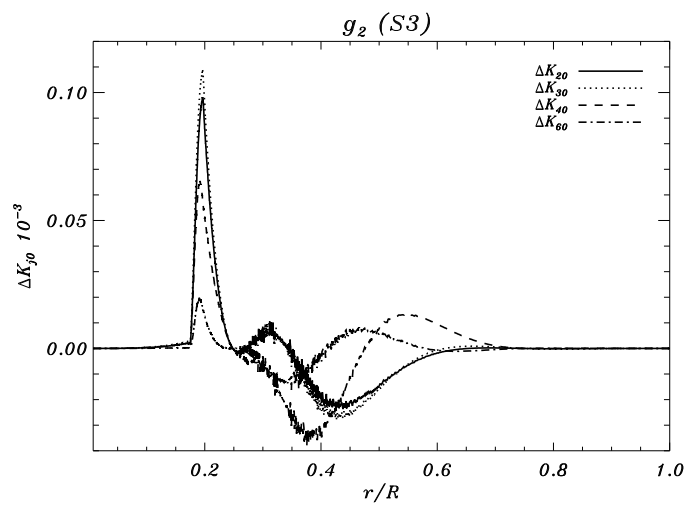

(a)

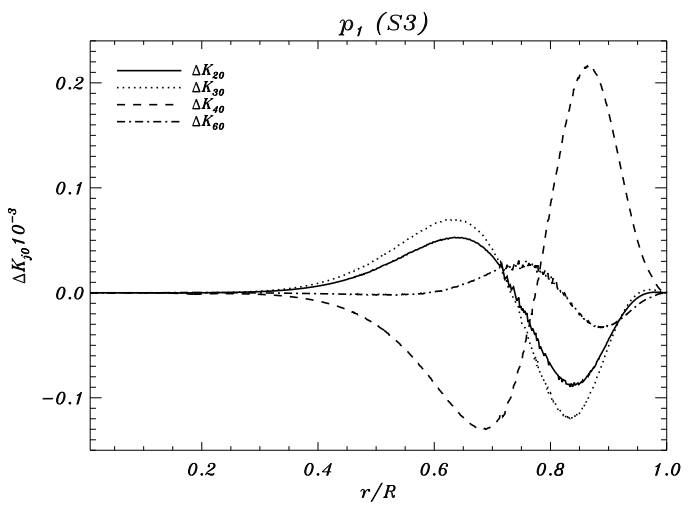

(c)

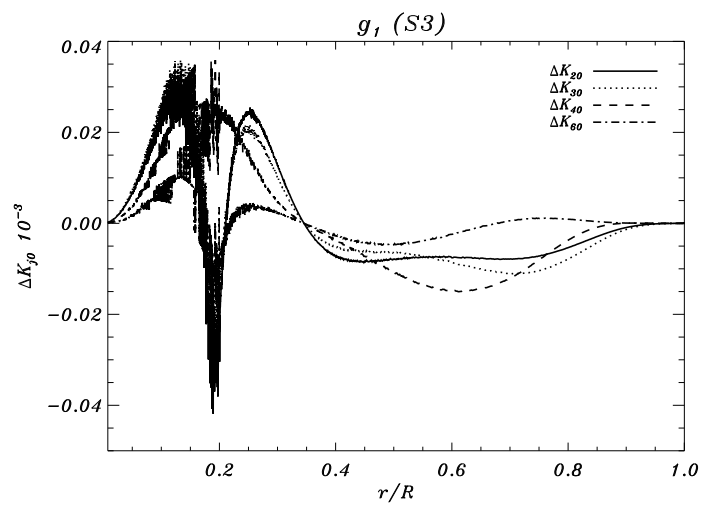

(b)

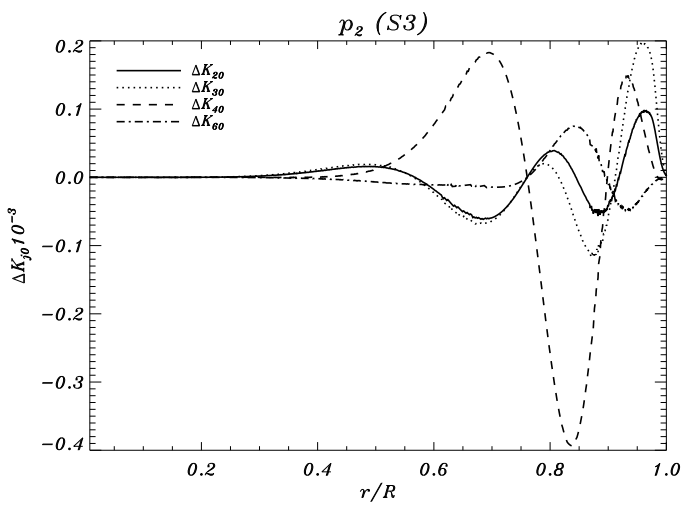

(d)

Figura 4.8: O mesmo que a figura 4.6 para modelos com ajuste polinomial do perfil de rotação. 


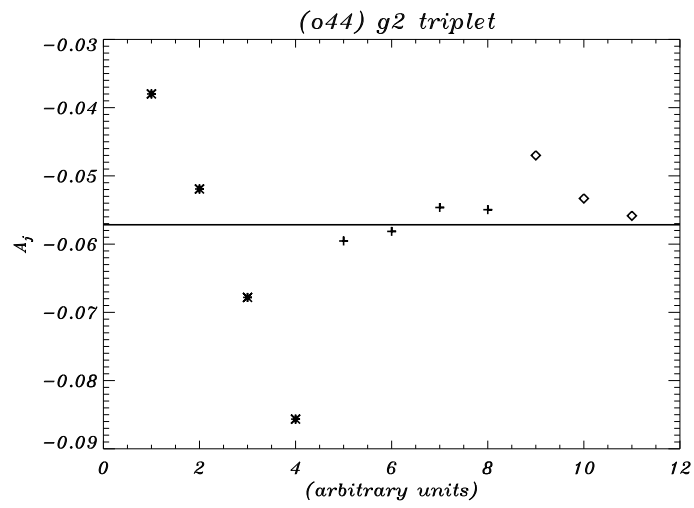

(a)

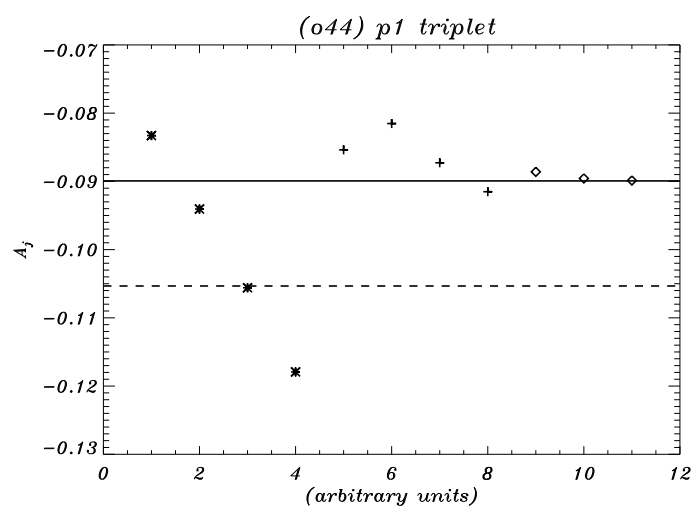

(c)

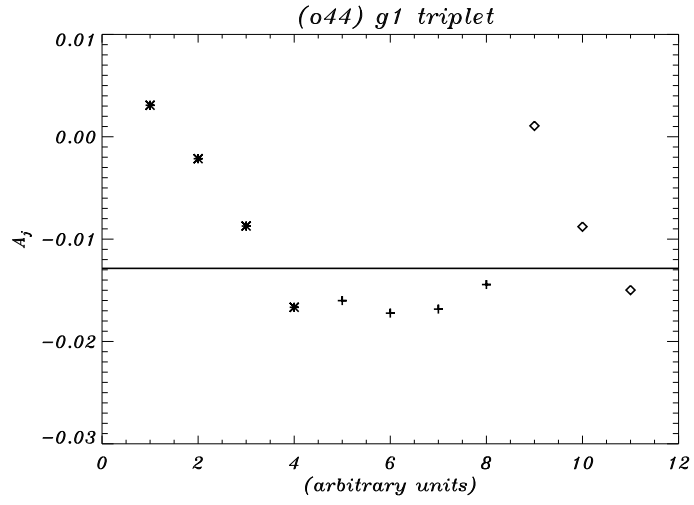

(b)

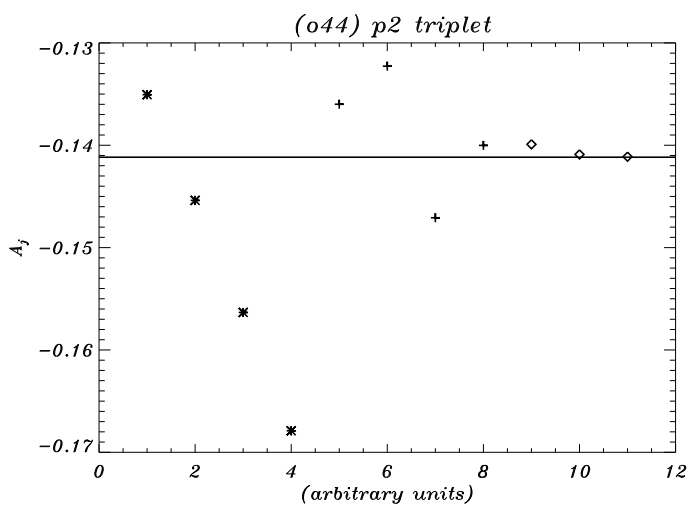

(d)

Figura 4.9: Assimetrias $\left(A_{j}\right)$ dos tripletos $g_{2}(\mathrm{a}), g_{1}(\mathrm{~b}), p_{1}(\mathrm{c})$ e $p_{2}(\mathrm{~d})$, computadas para os 12 perfis de rotação considerados. A linha reta representa, em cada caso, a assimetria do modelo de referência (modelo 2 na tabela 4.1). A linha hachurada em (c) representa a assimetria observada de $\theta$ Ophiuchi conforme determinada por Handler et al. (2005). Para identificar os modelos consideramos a seguinte representação: asteriscos para modelos de perfil linear (da esquerda para a direita, modelos vão de $\eta_{s}=25 \%$ para $100 \%$, respectivamente), cruzes para modelos polinomiais (da esquerda para a direita, modelos vão da ordem 2 para ordem 6), e losangos para modelos "shellulares" (da esquerda para a direita, modelos vão de $\eta_{s}=25 \%$ até $75 \%$, respectivamente). 


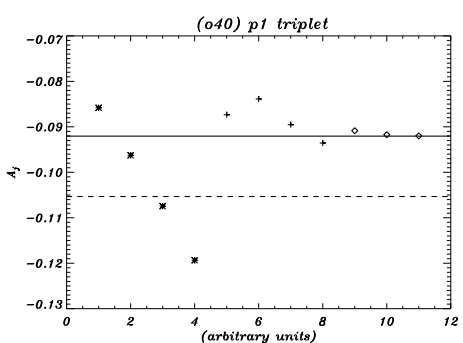

(a)

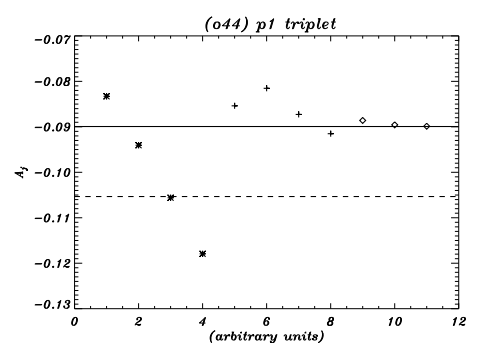

(b)

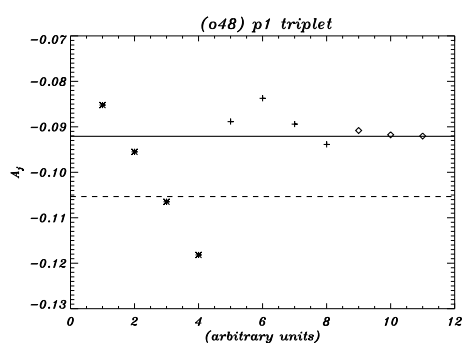

(c)

Figura 4.10: Assimetrias $\left(A_{j}\right)$ do tripleto $p 1$ computadas para as 12 variações de perfis para os três modelos na tabela 4.1. A linha reta representa, em cada caso, a assimetria do modelo de referência. A linha hachurada representa a assimetria observada de $\theta$ Ophiuchi conforme determinada por Handler et al. (2005).

\begin{tabular}{llllllllll}
\hline \hline & $\omega_{0}$ & $X_{1}$ & $X_{2}$ & $Y_{1}^{I}$ & $Y_{1}^{T}$ & $Y_{1}^{P}$ & $Y_{1}^{0}$ & $Y_{1}$ & $Y_{2}$ \\
\hline ref & 1.2007 & 0.7482 & 0.0945 & -0.0387 & -0.187 & -0.856 & 0.25 & -0.8317 & -0.1417 \\
$\operatorname{lin} 100$ & 1.2008 & 0.929 & 0.1223 & -0.0872 & -0.2322 & -1.253 & 0.3136 & -1.2588 & -0.1835 \\
$\operatorname{lin} 75$ & 1.2008 & 0.7873 & 0.1081 & -0.0744 & -0.1968 & -0.985 & 0.266 & -0.9903 & -0.1621 \\
$\operatorname{lin} 50$ & 1.2007 & 0.6575 & 0.0948 & -0.0625 & -0.1644 & -0.7459 & 0.2223 & -0.7505 & -0.1421 \\
$\operatorname{lin} 25$ & 1.2007 & 0.5394 & 0.0824 & -0.0515 & -0.1349 & -0.5358 & 0.1825 & -0.5397 & -0.1237 \\
shell75 & 1.2007 & 0.734 & 0.0941 & -0.0403 & -0.1835 & -0.8337 & 0.2462 & -0.8113 & -0.1411 \\
shell50 & 1.2007 & 0.6987 & 0.093 & -0.067 & -0.1747 & -0.7661 & 0.2357 & -0.7721 & -0.1395 \\
shell25 & 1.2007 & 0.6055 & 0.0911 & -0.0637 & -0.1514 & -0.6663 & 0.2049 & -0.6764 & -0.1366 \\
poly6 & 1.2007 & 0.7363 & 0.0925 & -0.0344 & -0.1841 & -0.8222 & 0.246 & -0.7948 & -0.1387 \\
poly4 & 1.2007 & 0.7832 & 0.0923 & -0.0471 & -0.1958 & -0.8515 & 0.2613 & -0.8331 & -0.1385 \\
poly3 & 1.2008 & 0.7513 & 0.091 & -0.0581 & -0.1878 & -0.8143 & 0.252 & -0.8082 & -0.1364 \\
poly2 & 1.2008 & 0.7649 & 0.0939 & -0.0582 & -0.1912 & -0.8531 & 0.2567 & -0.8459 & -0.1409 \\
\hline
\end{tabular}

Tabela 4.2 - Valores dos coeficientes de segunda ordem $X_{i}$ e $Y_{i}$ (Suárez et al. 2006) para o modo $g_{2}(l=1)$, calculados para o modelo de referência (modelo 1 na tabela 4.1 e modelos com perfis de rotação modificados para os três cenários discutidos. 


\begin{tabular}{llllllllll}
\hline \hline & $\omega_{0}$ & $X_{1}$ & $X_{2}$ & $Y_{1}^{I}$ & $Y_{1}^{T}$ & $Y_{1}^{P}$ & $Y_{1}^{0}$ & $Y_{1}$ & $Y_{2}$ \\
\hline ref & 2.307 & 0.8636 & 0.1953 & 0.1762 & -0.2159 & -0.3649 & 0.2468 & -0.1578 & -0.2929 \\
$\operatorname{lin} 100$ & 2.307 & 0.9027 & 0.2409 & 0.122 & -0.2257 & -0.3848 & 0.2594 & -0.2291 & -0.3613 \\
$\operatorname{lin} 75$ & 2.307 & 0.7474 & 0.2135 & 0.0967 & -0.1869 & -0.1364 & 0.2148 & -0.0118 & -0.3203 \\
$\operatorname{lin} 50$ & 2.307 & 0.6067 & 0.1884 & 0.0743 & -0.1517 & 0.0699 & 0.1744 & 0.167 & -0.2826 \\
$\operatorname{lin} 25$ & 2.307 & 0.4806 & 0.1654 & 0.0549 & -0.1202 & 0.2343 & 0.1382 & 0.3073 & -0.2482 \\
shell75 & 2.307 & 0.8252 & 0.1964 & 0.076 & -0.2063 & -0.3324 & 0.2365 & -0.2262 & -0.2945 \\
shell50 & 2.307 & 0.6873 & 0.1937 & 0.0571 & -0.1718 & -0.1203 & 0.1975 & -0.0375 & -0.2906 \\
shell25 & 2.307 & 0.5184 & 0.1773 & 0.0533 & -0.1296 & 0.183 & 0.1491 & 0.2557 & -0.266 \\
poly6 & 2.307 & 0.865 & 0.2005 & 0.1586 & -0.2163 & -0.3872 & 0.2476 & -0.1972 & -0.3008 \\
poly4 & 2.307 & 0.9209 & 0.2083 & 0.1519 & -0.2302 & -0.4761 & 0.2638 & -0.2906 & -0.3125 \\
poly3 & 2.307 & 0.8233 & 0.201 & 0.1456 & -0.2058 & -0.4385 & 0.2361 & -0.2626 & -0.3015 \\
poly2 & 2.307 & 0.8334 & 0.2051 & 0.1523 & -0.2084 & -0.4173 & 0.239 & -0.2344 & -0.3077 \\
\hline
\end{tabular}

Tabela 4.3 - Valores dos coeficientes de segunda ordem $X_{i}$ e $Y_{i}$ (Suárez et al. 2006) para o modo $g_{1}(l=1)$, calculados para o modelo de referência (modelo 1 na tabela 4.1 e modelos com perfis de rotação modificados para os três cenários discutidos. 


\begin{tabular}{llllllllll}
\hline \hline & $\omega_{0}$ & $X_{1}$ & $X_{2}$ & $Y_{1}^{I}$ & $Y_{1}^{T}$ & $Y_{1}^{P}$ & $Y_{1}^{0}$ & $Y_{1}$ & $Y_{2}$ \\
\hline ref & 3.5385 & 0.9216 & 3.4229 & -0.5629 & -0.2304 & 0.7645 & 0.5552 & 0.5264 & -5.1343 \\
$\operatorname{lin} 100$ & 3.5383 & 1.1509 & 4.1156 & -0.7093 & -0.2877 & 0.5218 & 0.6916 & 0.2164 & -6.1734 \\
$\operatorname{lin} 75$ & 3.5384 & 1.0487 & 3.84 & -0.6437 & -0.2622 & 0.6672 & 0.6319 & 0.3932 & -5.76 \\
$\operatorname{lin} 50$ & 3.5384 & 0.952 & 3.575 & -0.5816 & -0.238 & 0.7954 & 0.5748 & 0.5506 & -5.3625 \\
$\operatorname{lin} 25$ & 3.5385 & 0.8606 & 3.3205 & -0.5231 & -0.2151 & 0.9063 & 0.5204 & 0.6885 & -4.9807 \\
shell75 & 3.5385 & 0.9208 & 3.4228 & -0.5624 & -0.2302 & 0.7669 & 0.5549 & 0.5291 & -5.1342 \\
shell50 & 3.5385 & 0.9174 & 3.4225 & -0.5609 & -0.2294 & 0.7789 & 0.5533 & 0.542 & -5.1337 \\
shell25 & 3.5385 & 0.9071 & 3.4215 & -0.5545 & -0.2268 & 0.8179 & 0.5479 & 0.5846 & -5.1322 \\
poly6 & 3.5385 & 0.926 & 3.4465 & -0.5645 & -0.2315 & 0.7429 & 0.5579 & 0.5048 & -5.1698 \\
poly4 & 3.5385 & 0.9432 & 3.6353 & -0.5716 & -0.2358 & 1.0031 & 0.5683 & 0.7639 & -5.4529 \\
poly3 & 3.5385 & 0.8293 & 3.0055 & -0.5095 & -0.2073 & 0.7001 & 0.4979 & 0.4811 & -4.5082 \\
poly2 & 3.5385 & 0.8721 & 3.1761 & -0.5352 & -0.218 & 0.7084 & 0.5241 & 0.4793 & -4.7642 \\
\hline
\end{tabular}

Tabela 4.4 - Valores dos coeficientes de segunda ordem $X_{i}$ e $Y_{i}$ (Suárez et al. 2006) para o modo $p_{1}(l=1)$, calculados para o modelo de referência (modelo 1 na tabela 4.1 e modelos com perfis de rotação modificados para os três cenários discutidos. 


\begin{tabular}{llllllllll}
\hline \hline & $\omega_{0}$ & $X_{1}$ & $X_{2}$ & $Y_{1}^{I}$ & $Y_{1}^{T}$ & $Y_{1}^{P}$ & $Y_{1}^{0}$ & $Y_{1}$ & $Y_{2}$ \\
\hline ref & 4.7191 & 0.9196 & 6.8247 & -0.561 & -0.2299 & 0.807 & 0.5561 & 0.5722 & -10.237 \\
$\operatorname{lin} 100$ & 4.7189 & 1.1112 & 7.7774 & -0.6822 & -0.2778 & 0.5743 & 0.667 & 0.2813 & -11.666 \\
$\operatorname{lin} 75$ & 4.719 & 1.0204 & 7.3961 & -0.6252 & -0.2551 & 0.7159 & 0.6159 & 0.4515 & -11.094 \\
$\operatorname{lin} 50$ & 4.7191 & 0.9348 & 7.0289 & -0.5716 & -0.2337 & 0.844 & 0.5669 & 0.6056 & -10.543 \\
$\operatorname{lin} 25$ & 4.7191 & 0.8546 & 6.6759 & -0.5214 & -0.2136 & 0.9585 & 0.5198 & 0.7433 & -10.014 \\
shell75 & 4.7191 & 0.9188 & 6.824 & -0.5616 & -0.2297 & 0.8097 & 0.5558 & 0.5743 & -10.236 \\
shell50 & 4.7191 & 0.9155 & 6.8229 & -0.561 & -0.2289 & 0.8218 & 0.5543 & 0.5863 & -10.234 \\
shell25 & 4.7191 & 0.8999 & 6.8184 & -0.5508 & -0.225 & 0.8718 & 0.5461 & 0.6422 & -10.228 \\
poly6 & 4.7191 & 0.9086 & 6.7496 & -0.5536 & -0.2271 & 0.8012 & 0.5494 & 0.5699 & -10.124 \\
poly4 & 4.7191 & 0.9695 & 7.4404 & -0.5927 & -0.2424 & 0.8927 & 0.5872 & 0.6448 & -11.161 \\
poly3 & 4.7191 & 0.8548 & 6.2099 & -0.5244 & -0.2137 & 0.8176 & 0.5149 & 0.5944 & -9.3149 \\
poly2 & 4.7191 & 0.8885 & 6.4671 & -0.5446 & -0.2221 & 0.8022 & 0.5356 & 0.5711 & -9.7006 \\
\hline
\end{tabular}

Tabela 4.5 - Valores dos coeficientes de segunda ordem $X_{i}$ e $Y_{i}$ (Suárez et al. 2006) para o modo $p_{2}(l=1)$, calculados para o modelo de referência (modelo 1 na tabela 4.1 e modelos com perfis de rotação modificados para os três cenários discutidos. 


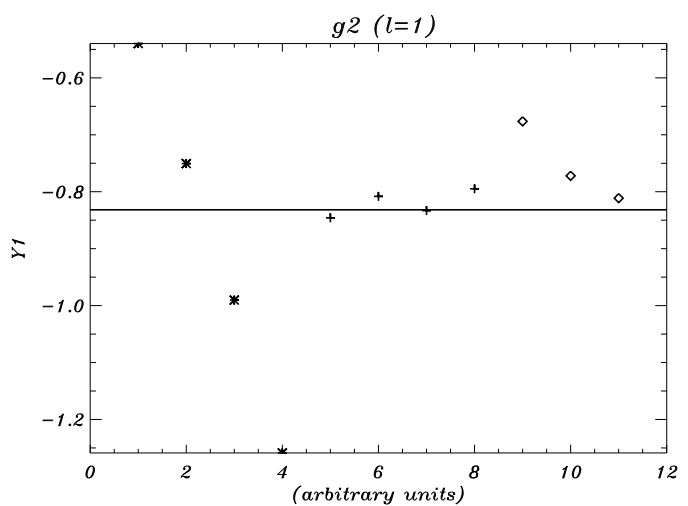

(a)

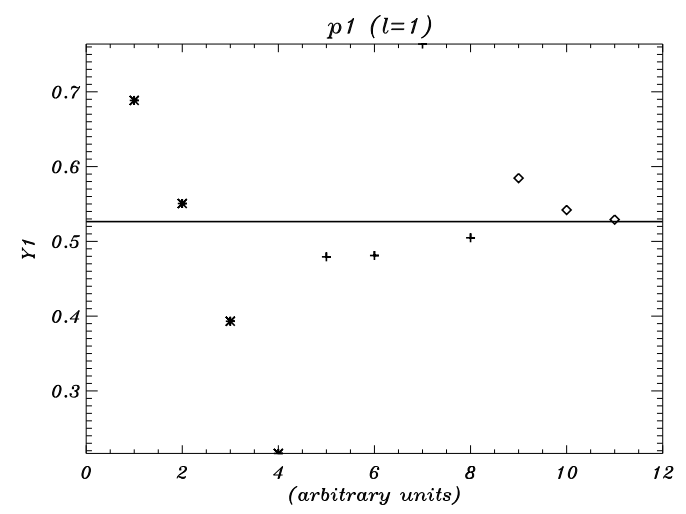

(c)

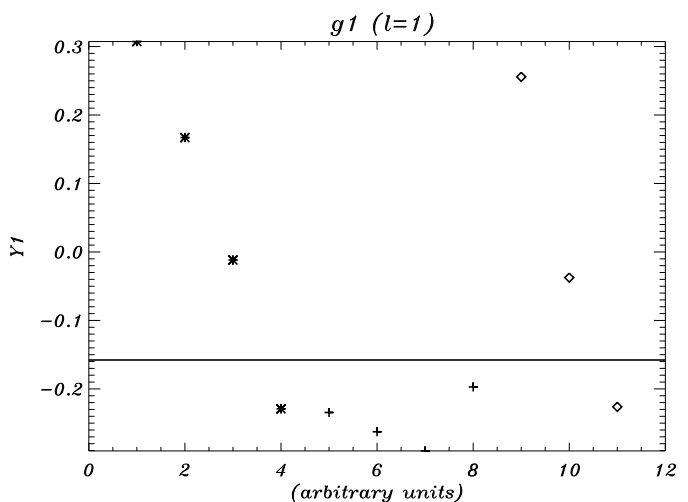

(b)

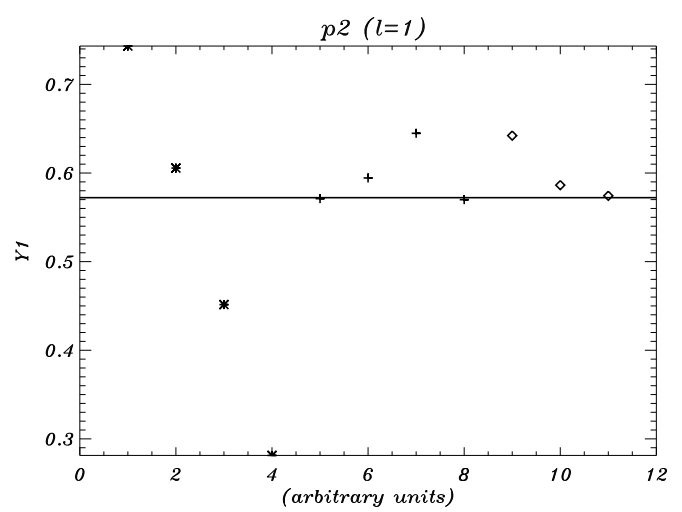

(d)

Figura 4.11: Termos $Y_{1}$ dos tripletos $g_{2}(\mathrm{a}), g_{1}(\mathrm{~b}), p_{1}(\mathrm{c})$ and $p_{2}(\mathrm{~d})$, computados para os 12 diferentes perfis de rotação considerados (modelo de referência 1 na tabela 4.1). A linha reta representa, em cada caso, o valor do modelo de referência. Para identificar os modelos consideramos a seguinte representação: asteriscos para modelos de perfil linear (da esquerda para a direita, modelos vão de $\eta_{s}=25 \%$ para $100 \%$, respectivamente), cruzes para modelos polinomiais (da esquerda para a direita, modelos vão da ordem 2 para ordem 6), e losangos para modelos "shellulares" (da esquerda para a direita, modelos vão de $\eta_{s}=25 \%$ até $75 \%$, respectivamente). 


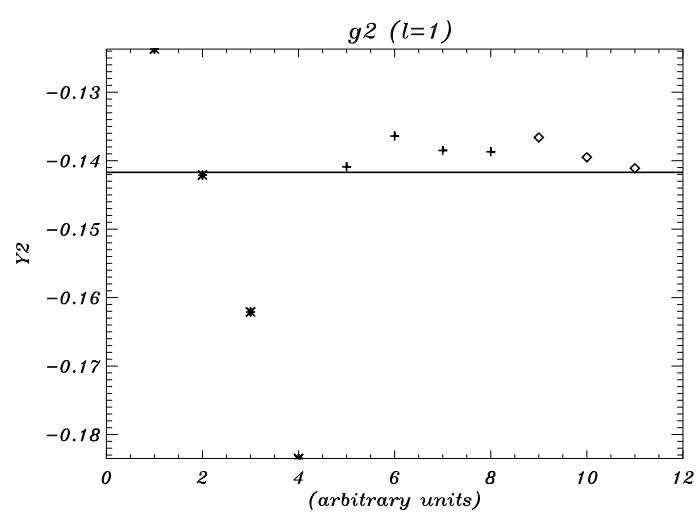

(a)

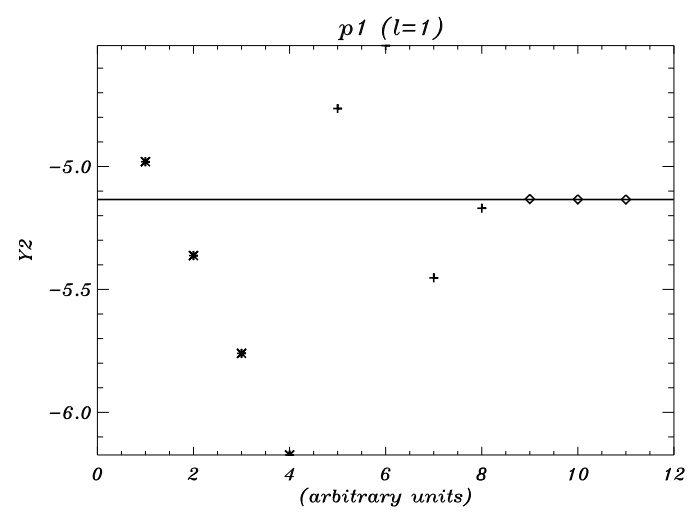

(c)

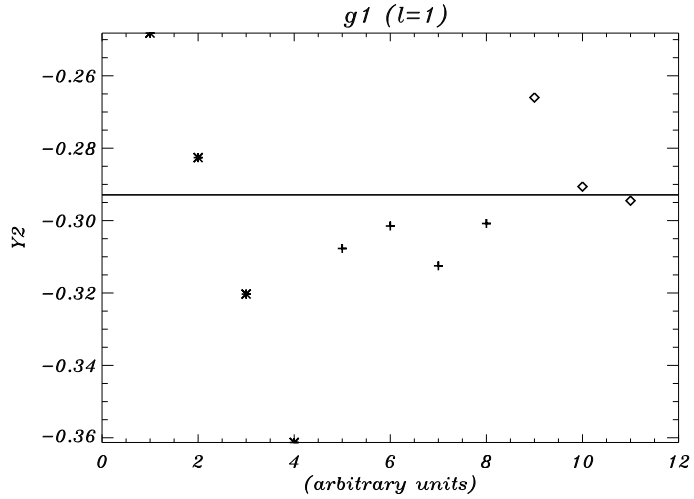

(b)

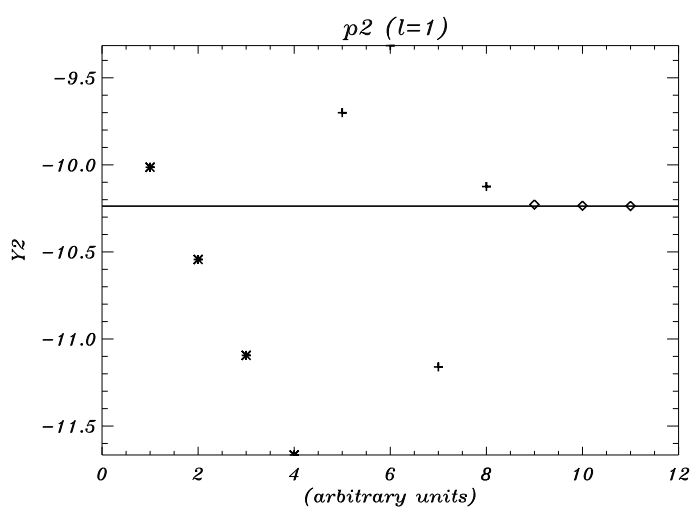

(d)

Figura 4.12: Termos $Y_{2}$ dos tripletos $g_{2}$ (a), $g_{1}$ (b), $p_{1}$ (c) and $p_{2}$ (d), computados para os 12 diferentes perfis de rotação considerados (modelo de referência 1 na tabela 4.1). A linha reta representa, em cada caso, o valor do modelo de referência. Modelos seguem a mesma representação da figura 4.11. 


\subsection{Identificação de modos de oscilação em estrelas Be de baixa rotação}

Estrelas Be clássicas são rotatores rápidos de tipo espectral entre $\mathrm{O}$ e A, com classes de luminosidade V-III, que contém linhas de Balmer em emissão em algum momento de sua vida, e um excesso no infravermelho próximo devido a existência de um envelope circumstelar concentrado equatorialmente, produzido por episódios de ejeção de massa episódicos. As causas dessa perda de massa anormal (o chamado fenômeno Be) ainda são desconhecidas. Apesar de valores altos de $v \sin i$ (Frémat et al. 2005), somente a rotação rápida não pode explicar os episódios de ejeção dado que a maioria das estrelas Be não giram com a velocidade crítica (Porter \& Rivinius, 2003).

Observações espectroscópicas de alta resolução e alta relação sinal-ruído mostraram que a presença de variações de curta duração é bastante comum entre estrelas Be mais quentes (ver por exemplo, Baade 1982, 1984; Porri \& Stalio 1988; Floquet et al. 1992; Neiner et al. 2002). A variação do perfil de linha observada (LPV, line profile variability) é caracterizada pela presença de elevações que movem-se do azul para o vermelho no perfil de linha em escalas de tempo que variam de alguns minutos para alguns dias. O fenômeno também já foi observado em estrelas do tipo O e variáveis $\delta$ Scuti (Kennely et al. 1992), entre outras.

Pulsações não-radiais foram propostas como uma explicação para a LPV observada em estrelas quentes (Smith, 1977; Baade 1982; Vogt \& Penrod 1983). NRPs produzem LPVs devido à combinação do deslocamento Doppler de elementos da superfície estelar com as variações de temperatura associadas devido à compressão/expansão causada pela passagem de ondas pela fotosfera. NRPs poderiam ser o mecanismo adicional necessário para uma estrela B de alta rotação transformar-se em uma Be, ou seja, iniciar o fenômeno Be por ejeção de massa. De fato, Rivinius et al. (1988) encontraram multiperiodicidades em $\mu$ Centauri e mostraram que uma correlação existe entre episódios de ejeção de matéria e o padrão de pulsações da multiperiodicidade. Encontrar novos casos de estrelas Be para as quais períodos pulsantes de NRPs multiperiódicas coincidem com ejeções de matéria ajudaria a confirmar tal modelo. A variação periódica da estrela foi reproduzida em deta-

lhes por modelamento de NRPs (Rivinius et al. 2001). LPVs de períodos curtos de outras estrelas Be também foram modeladas usando NRPs.

Mais recentemente, observações do satélite MOST mostraram que multiperiodicidades 
devidas a NRPs é um fenômeno bastante comum entre estrelas Be (Walker et al. 2005; Dziembowski et al. 2007). No entanto, encontrar frequências com grande precisão em estrelas requer tanto alta precisão fotométrica quanto alta resolução temporal. O satélite CoRoT permitiu cumprir tais exigências.

\subsubsection{Estrela Corot-ID 102761769 - observações fotométricas}

Concentramos nesse trabalho na análise da estrela CoRoT-ID 102761769. Devido a uma certa instabilidade do sistema de controle de atitude do satélite, a análise de certas estrelas requeriu um tratamento cuidadoso.

Os dados foram observados no campo exo durante o Initial Run (IRa01), durante 54.6 dias com uma cadência inicial de 512 segundos. Após 3.13 dias CoRoT começou a gravar os dados de ID 102761769 com uma cadência de 32 segundos (figura 1 do anexo 2). As coordenadas da estrela (J2000.0) são RA $=06^{\mathrm{h}} 45^{\mathrm{m}} 02^{\mathrm{s}} .4$ e DEC $=-01^{\circ} 50^{\prime} 08^{\prime \prime} .3$, com magnitude $V=13.08$ mag. A estrela é citada em catálogos que mencionam objetos com linhas de emissão (Kohoutek \& Wehmeyer 1999; Robertson \& Jordan 1989). A curva de luz contém 129305 observações fotométricas. Buscando por oscilações, aplicamos o algoritmo Cleanest (Foster, 1995) aos dados (detalhes no anexo 2), resultando em duas frequências identificadas, $2.465 c d^{-1}$ e $2.441 c d^{-1}$.

\subsubsection{Observações espectroscópicas em terra}

Um espectro de CoRoT-ID 102761769 foi obtido no Observatorio del Roque de los Muchachos em 30 de Março de 2008, com o Intermediate Dispersion Spectrograph (IDS) no telescópio de Isaac Newton de 2.5m de diâmetro. O espectro foi feito com 300 segundos de tempo de exposição, usando rede de 300 l/mm centrada em $5460 \AA$ e cobrindo a região de $3337 \AA$ até $8366 \AA$ e resolução de $2 \AA$ (figura 4.13). A figura 4.14 mostra as regiões de $\mathrm{H} \alpha$, $\mathrm{H} \beta$ e He $4471 \AA / \mathrm{Mg} 4481 \AA$. A redução foi feita com pacote IRAF. H $\alpha$ é visto em emissão e $\mathrm{H} \beta$ está parcialmente preenchida em emissão. As características espectrais sugerem um tipo espectral B5-6 IV-Ve baseado nas larguras equivalentes das linhas de $\mathrm{HeI}, \mathrm{H} \delta, \mathrm{H} \gamma$ e Mg II $(\lambda 4481 \stackrel{\circ}{A})$.

Cuidados usuais devem ser tomados com a classificação espectral de estrelas Be que pode ser influenciada pelo envelope circumstelar e gravitational darkening. A velocidade de 
rotação foi estimada pelo cálculo do primeiro zero da transformada de Fourier de diversas linhas de He. Concluímos que a estrela gira com no máximo $v \sin i=120 \pm 15 \mathrm{~km} / \mathrm{s}$. Trata-se de um valor máximo da velocidade projetada devido a resolução do espectro disponível.

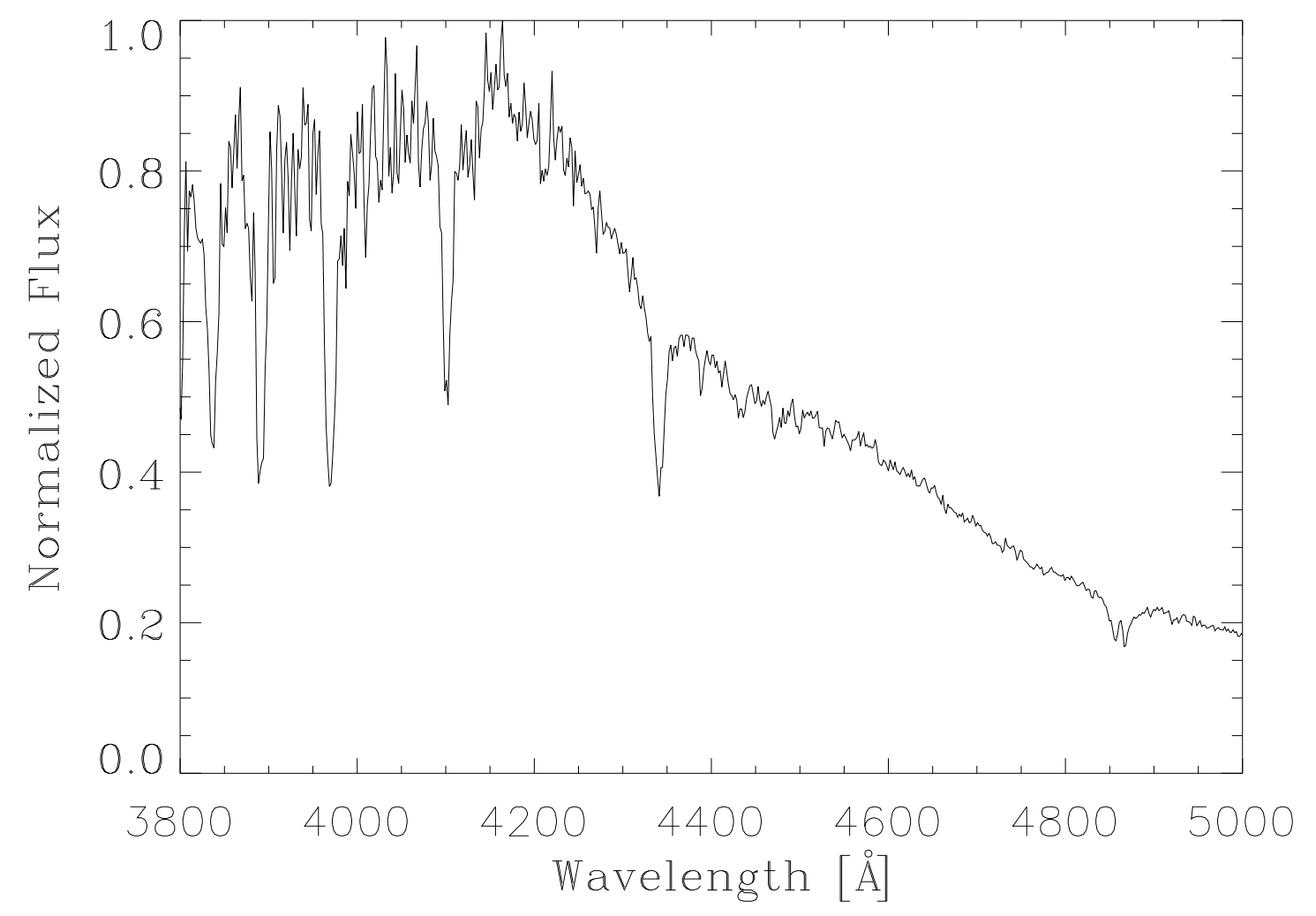

Figura 4.13: Observação espectroscópica da estrela CoRoT-ID 102761769.

\subsubsection{Pulsações não-radiais}

De modo a identificar os modos de pulsação das frequencias observadas, computamos uma série de modelos representativos da estrela Be CoRoT 102761769, variando seus parâmetros físicos principais dentro das incertezas determinadas observacionalmente. Essas foram basicamente sua massa $\left(M=3.8 \pm 0.2 M_{\odot}\right)$ e velocidade de rotação equatorial $\left(v_{r o t, s}=90\right.$ or $120 \mathrm{~km} / \mathrm{s}$ ), assumindo uma abundância solar (figura 4.15). Para uma série de modelos com 3.8 massas solares e $v_{r o t, s}=120 \mathrm{~km} / \mathrm{s}$, também variamos o overshooting no núcleo convectivo. Os modelos de estrutura foram calculados usando o código de evolução 

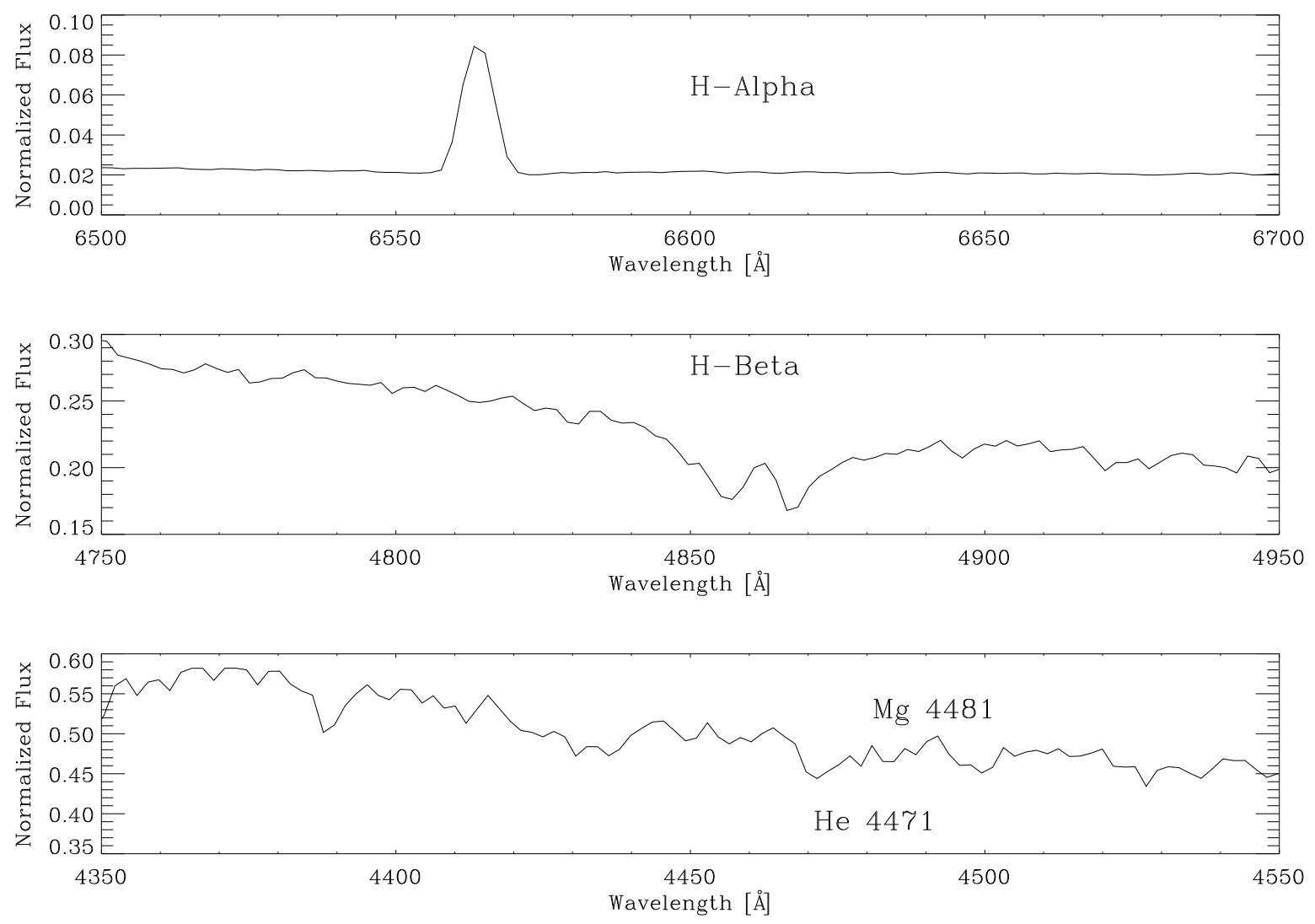

Figura 4.14: Close-ups de regiões espectrais de interesse. De cima para baixo: $\mathrm{H} \alpha, \mathrm{H} \beta, \mathrm{He} 4471 \AA$ A $/ \mathrm{Mg}$ $4481 \AA$ 
Tabela 4.6 - Modelos que melhor se aproximam da frequência observada $f_{1}$ para cada uma dos seis traçados de evolução considerados. As frequências são todas compatíveis com um modo de pulsação $g_{5}$ $(l=1, m=0)$.

\begin{tabular}{llll}
\hline \hline $\operatorname{mass}\left(M_{\odot}\right)$ & $v_{\text {rot }, s}(\mathrm{~km} / \mathrm{s})$ & idade $(\mathrm{Myr})$ & $\nu(\mu \mathrm{Hz})$ \\
\hline 3.6 & 90 & 5 & 29.314 \\
3.6 & 120 & 4 & 30.326 \\
3.8 & 90 & 65 & 28.575 \\
3.8 & 120 & 65 & 29.112 \\
4.0 & 90 & 75 & 28.622 \\
4.0 & 120 & 70 & 28.502 \\
\hline
\end{tabular}

CESAM, assumindo rotação diferencial.

Frequências de oscilação foram então derivadas usando o pacote de pulsações adiabáticas FILOU, assumindo efeitos de rotação até segunda ordem. Os espectros de frequência resultantes foram então analisados em busca dos modos que melhor aproximam as frequências observadas $f_{1}$ e $f_{2}$, dentro de uma incerteza na temperatura efetiva derivada de Huang \& Gies (2006) como sendo $\log \left(T_{\text {eff }}\right)=4.16 \pm 0.01$ ) para uma estrela B5-6V. O valor central considerado para a temperatura efetiva foi aquele de uma estrela de 3.8 massas solares no meio da sequência principal. Os resultados, mostrados na tabela 4.6, indicam que, para todos os modelos considerados, as frequências só podem ser descritas por um modo g alto, em particular $g_{5}(l=1, m=0)$, ao contrário do modo de baixo g que seria esperado.

A figura 4.16 mostra para um conjunto de modelos representativo como essa diferença se expressa. Utilizando o procedimento de variação de perfil de rotação descrito na seção anterior, poderemos tentar encontrar alguma relação entre o perfil interno de rotação de estrelas Be e suas frequências de oscilação observadas. 


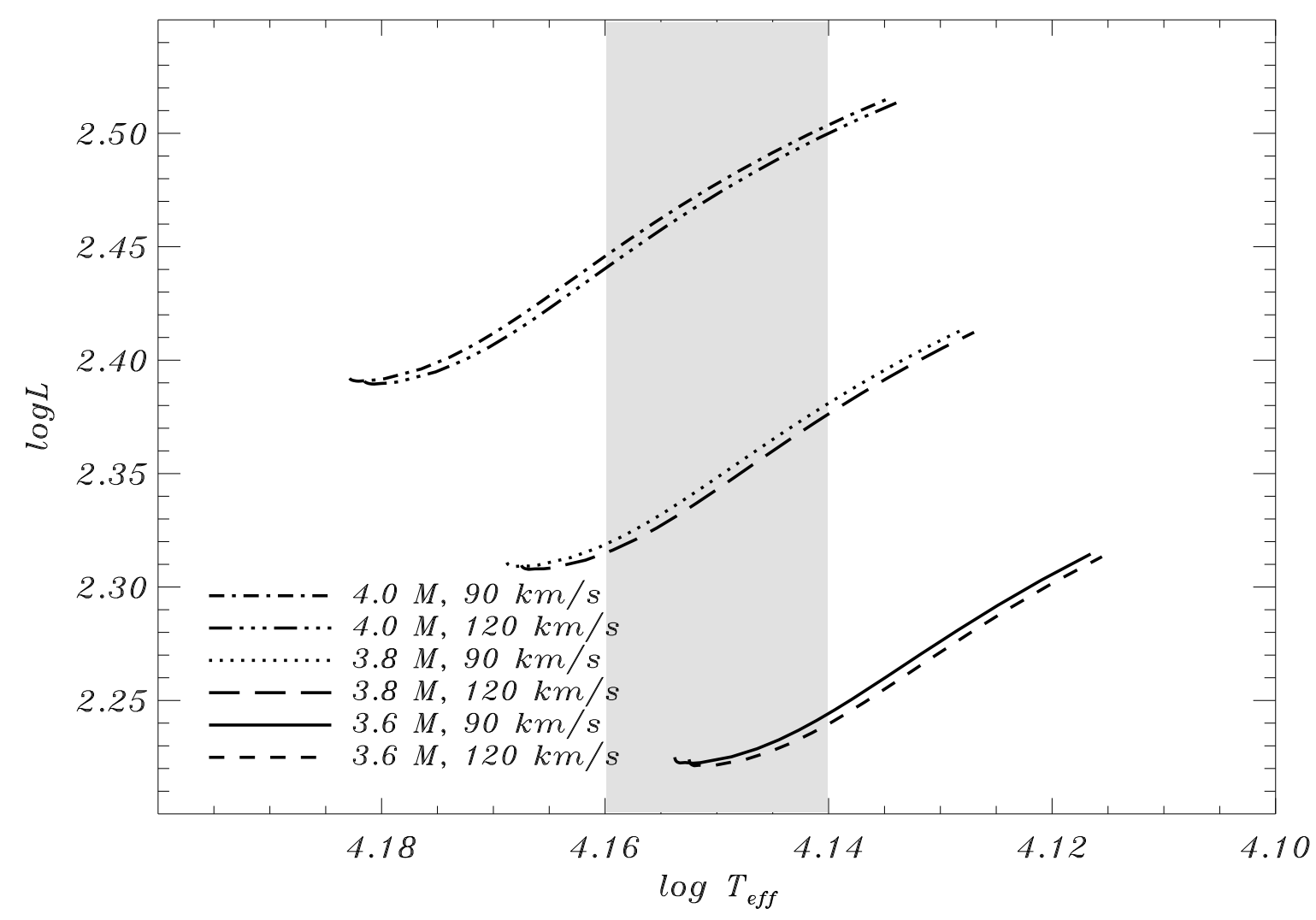

Figura 4.15: Diagrama HR mostrando traçados evolutivos calculados para CoRoT 102761769, para três diferentes valores de massa $\left(3.6,3.8\right.$ and $\left.4.0 M_{\odot}\right)$ e duas velocidades de rotação equatorial (90 e $120 \mathrm{~km} / \mathrm{s}$ ). A área hachurada corresponde a incerteza na temperatura efetiva. 


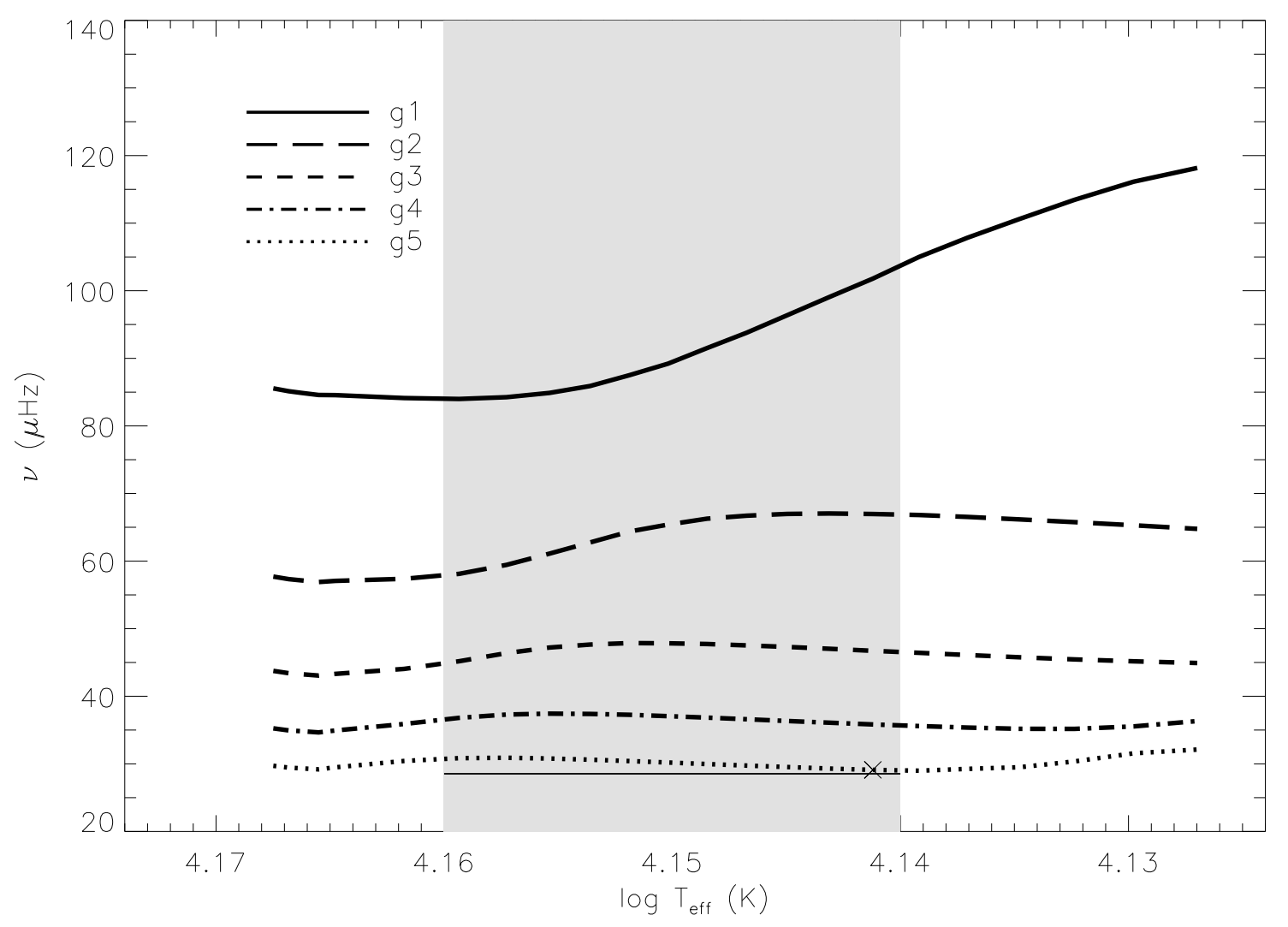

Figura 4.16: Frequências dos modos $g_{1}$ a $g_{5}(l=1, m=0)$ em $\mu \mathrm{Hz}$ em função da temperatuva efetiva para conjuntos de modelos com 3.8 massas solares e $v_{r o t, s}=120 \mathrm{~km} / \mathrm{s}$. A caixa cinza representa a incerteza em $T_{\text {eff }}$ tal qual derivada a partir de Huang \& Gies (2006). A linha horizontal representa a frequência $f_{1}$ observada. A cruz marca o modelo mais próximo de $\nu\left(g_{5}, m=0\right)$ observado. 
Capítulo 5

\section{Conclusões e Perspectivas}

O objetivo do trabalho consistiu em melhorar a qualidade de modelos de estrelas quentes de rotação moderada, de forma a poder cotejá-los com as características observacionais de pulsações não-radiais num processo iterativo que conduz a determinação, com maior precisão, dos parâmetros físicos e a estrutura interna de tais estrelas. Em particular, procuramos determinar o perfil radial de rotação no interior dos objetos. Os satélites da geração atual (CoRoT, Kepler, etc.) permitem medir os parâmetros das pulsações nãoradiais com grande sensibilidade de detecção e grande poder de resolução de freqüências.

Nesta tese, apresentamos os últimos resultados de nossos cálculos, cotejados com resultados obtidos a partir de observações fotométricas e espectroscópicas (Handler et al. 2005) da estrela de tipo $\beta$ Cephei $\theta$ Ophiuchi ( $v \sin i=29 \pm 7 \mathrm{~km} / \mathrm{s}$, Briquet et al. 2007), e também da estrela do tipo Be CoRoT-ID $102761769(v \sin i \leq 120 \mathrm{~km} / \mathrm{s})$.

Procedemos primeiro calculando com o código computacional perturbativo existente (FILOU, Suárez et al. 2006) modelos de uma estrela que reproduzam bem as freqüências centrais e os splittings observados de $\theta$ Oph (figuras 4.2 e 4.3).

A partir destes modelos, criamos outros similares mas com distintos perfis de rotação interna: perfis lineares, "shellulares" ou com ajuste de um polinômio sobre o perfil original (figura 4.4).

Então analisamos:

1. a variação do valor de termos das equações de perturbação de segunda ordem com os diferentes perfis. Identificamos quais têm mais influência na variação das assimetrias de distintos modos. A comparação é feita com o modelo que possui o perfil de rotação padrão (saída do código de estrutura e evolução estelar, CESAM, Suárez et al. 2006); 
2. a variação do kernel para os diferentes perfis, o que permite comparar a mudança da energia de modos de pulsação ao longo do raio da estrela. Novamente, vemos quais suas possíveis influências sobre a variação das assimetrias (figuras 4.5, 4.6, 4.7 e 4.8).

Com tal procedimento, conseguimos:

1. identificar as características do perfil de rotação interna das estrelas quentes, indispensável para fazer modelos mais realistas; e

2. simplificar o problema: refazemos o código de cálculo perturbativo contendo apenas os termos dominantes quanto à sensibilidade à rotação, tornando mais preciso e eficiente o cálculo de pulsações não-radiais para as estrelas estudadas.

Prosseguiremos com o trabalho de cálculo de estrutura interna de estrelas quentes e a consequente determinação de seus parâmetros físicos, via cotejo com as observações de alta resolução em frequências dos satélites CoRoT e Kepler. Esperamos que, em um futuro próximo, isso possa nos levar à modelização de estrelas com rotação rápida. 


\section{Referências Bibliográficas}

Allen, M.R., \& Smith, L.A. 1996, Journal of Climate, 9, 3373

Angulo, C., Arnould, M., Rayet, M. and the NACRE collaboration 1999, Nuclear Physics A $656,3-183$

Auvergne, M., Boisnard, L., Lam-Trong, T., et al., 2009, A\&A, 506, 411

Baade, D. 1982, A\&A, 105, 65

Baade, D. 1984, A\&A, 135, 101

Böhm-Vitense, E. 1958, Zs.f.Astrophys. 46, 108

Boisnard, L., \& Auvergne, M. 2004, CoRoT mission engineering, IAC-04-IAFQ. 1.01

Briquet, M., Morel, T., Thoul, A., Scuflaire, R., Miglio, A., Montalbán, J., Dupret, M.-A., Aerts, C. 2007, Asteroseismology of $\theta$ Ophiuchi: constraints on global stellar parameters and core overshooting, MNRAS 381, 1482

Canuto, V.M. \& Mazzitelli, I. 1991, ApJ, 370, 295-311

Caughlan, G.R., Fowler, W.A. 1988, Thermonuclear Reaction Rates V. Atomic Data and Nuclear Data Tables 40, 284-334

Christensen-Dalsgaard, J. \& Dappen, W. 1992, A\&ARv 342, 267-361

Christensen-Dalsgaard, J. \& Dziembowski, W.A. 2000, Basic aspects of stellar structure and pulsation. In: Variable Stars as Essential Astrophysical Tools, Ibanoglu, C. (ed.). Kluwer Academic Publishers; 1-57 
Christensen-Dalsgaard, J. 2003, Stellar Oscillations, 5th ed., Aarhus Universitet, Danemark

Cox, J.P \& Giuli, R.T. 1968, Principles of Stellar Structure, vol I \& II, Gordon \& Brecht, New York

Cowling, T.G. \& Newing, R.A., 1949, The oscillations of a rotating star. ApJ, 109, 149-158

Dachs, J., Hanuschik, R., Kaiser, D., Rohe, D. 1986, A\&A, 159, 276

De Boor, C. 1978, A Practical Guide to Splines, Springer, 3rd ed.

Dziembowski, W.A., Daszynska-Daszkiewicz L., Pamyatnykh, A.A. 2007, MNRAS 374, 248

Dziembowski, W.A. \& Goode, P.R. 1992, ApJ, 394, 670

Eggleton, P. 1971, MNRAS, 151, 351

Eggleton, P.P,, Faulkner, J., Flannery, B.P. 1973, A\&A 23, 325

Frémat, Y., Zorec, J., Hubert, A.-M., Floquet, M. 2005, A\&A, 440,305

Floquet, M., Hubert, A.-M., Janot-Pacheco, E., et al 1992, A\&A, 264, 177

Foster G. 1995, ApJ, 109, 1889

Ghil, M., Allen, M.R., Dettinge, M.D. 2002, Reviews of Geophysics, 40, 1

Handler, G., Shobbrook, R.R. and Mokgwetsi, T. 2005, An asteroseismic study of the $\beta$ Cephei star $\theta$ Ophiuchi: photometric results. MNRAS, 362, 612

Huang, W., Gies, D.R., 2006, ApJ 648, 451

Hubert, A.M., Neiner, C., Floquet, M. et al. Be stars with $6<V<9$ in the cones of CoRoT, 4th COROT Week, Marseille, 2-6 Junho de 2003

Janot-Pacheco, E., Jankov, s., Leister, N.V., Hubert, A.M., Floquet, M. 1999, A\&A Supp. $137,407-418$

Kennely, E.J., Walker, G.A.H., Merryfield, W.J. 1992, ApJ, 400, L71 
Kepler, S.O. et al. 1995, ApJ 447, 874

Kippenhahn, R. \& Weigert, A. 1990, Stellar structure and evolution, Springer-Verlag

Kohoutek, L. \& Wehmeyer, R. 1999, A\&AS, 134, 255

Ledoux, P., 1949, Mem.Soc.R.Sci.Liège, 4th ser., 9, 3-294

Levenhagen, R.S., Leister, N.V, Zorec, J., Janot-Pacheco, E. et al. 2003, A\&A 400, 599-612

Neiner, C., Hubert, A. M., Floquet, M., et al. 2002, A\&A, 388, 899

Porri, A., Stalio, R. 1988, A\&ASS, 75, 371

Porter, J.M.,\& Rivinius, T. 2003, PASP, 115, 1153

Rivinius, Th., Baade, D., Stefl, S., et al. 1998, A\&A, 333,125

Rivinius, Th., Baade, D., Stefl, Maintz, M. 2001, A\&A, 369, 1058

Robertson, T.H. \& Jordan, T.M. 1989, AJ, 98, 1354

Schumaker, L. 1981, Splines Functions: Basic Theory, John Whiley, New York

Smith, M.A. 1977, ApJ, 215, 574

Morel, P., 1997, CESAM: A code for stellar evolution calculations, Astron.Astrophys.Suppl.Ser. 124, 597-614.

Soufi, F., Goupil, M.J., Dziembowski, W.A. 1998, A\&A 334, 911

Steele, I.A., Negueruela, I., Clarck, J.S. 1999, A\&AS 137, 147

Sterken, C., Jerzykiewicz, M. 1993, Beta Cephei stars from a photometric point of view. Space Science Reviews, 62, 95-171

Suárez, J.C. 2002, Ph.D. Thesis, ISBN 84-689-3851-3, ID 02/PA07/7178

Suárez, J.C., Michel, E., Pérez Hernández, F. et al. 2002, A\&A, 390, 523

Suárez, J.C., Goupil, M.J., \& Morel, P. 2006, Effects of moderately fast shellular rotation on adiabatic oscillations, A\&A 449, 673 
Townsend, R.H.D. 1997, Spectroscopic modeling of non-radial pulsation in rotating earlytype stars MNRAS 284, 389

Tran Minh, F. \& Léon, L. 1995, in Roxburg, I. W., Maxnou, J.L., eds., Physical Processes in Astrophysics. Lectures Notes in Physics. Springer Verlag, Berlin, 219

Unno, W., Osaki, Y., Ando, H., Saio, H., Shibahashi, H. 1989, Nonradial Oscillations of Stars, 2nd ed., University of Tokyo Press

Vinicius, M.M.F., Zorec, J., Leister, N.V., Levenhagen, R.S. 2006, A\&A 446, 643-660

Vogt, S.S., \& Penrod G.D. 1983, ApJ, 275,661

Walker, G.A.H., Kuschnig, R., Mathews, J.M., et al. 2005, ApJ, 635, L77

Zorec, J., Frémat, Y., Cidale, L. 2005, A\&A, 441, 235 
Apêndice 

Apêndice A

Analysis of asymmetries in rotational splitted multiplets of $\beta$ Cephei stars 
Apêndice B

Photometric variability of the Be star CoRoT-ID 102761769 